\title{
(IC'II). 17530-89
}

Revision 8

The Computational Physics Program of the National MFE Computer Center

Arther A. Mirin

January 1989

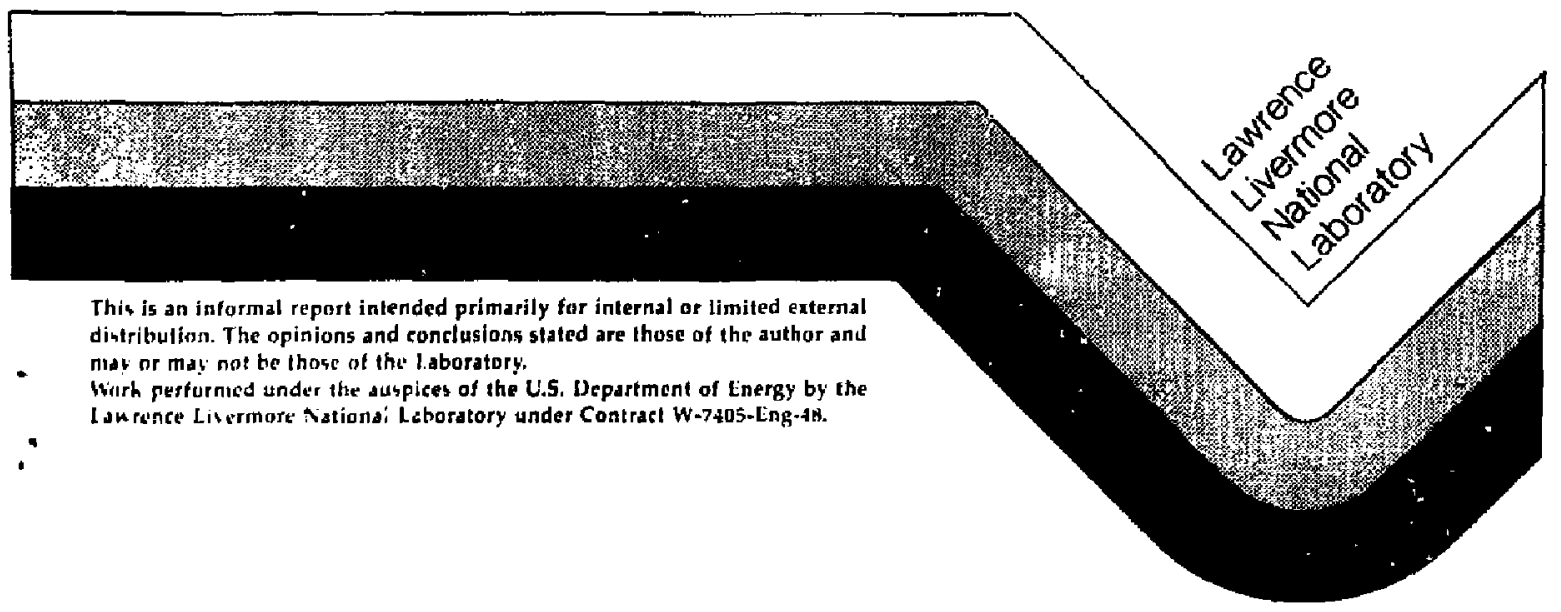

F.TPO QDUCED FROM

$\therefore$ AAlLAQLE COPY

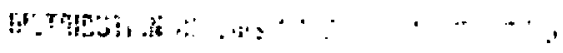


This doxument was prepared as an account of wort epongored by an agency of the Unifed Sbate Covernment. Neither the United States Covemment nor the Univenfly of Californil nor inf of their employert, makes any wrraaly, express or implied, or ansumes any Irgal liability or reoponsibility for the accuracy, completeness, or ubefriness of any intomation, opparatus, praduct, or procens dixclosed, or represents that its wse would not infringe privalely owned righto, Reference hetetir lo any apecifle commerclal products, procesa, of service by trade name, trademark, masufactures, ot otherwise, dows not necengrily conatitute or imply its endoroement. cecominendation, or fuvoring by the Uniled States Covernmedt or the Univerilly of California. The viewi and opinions of authors expresed herein do not necesarily wale or reflect thase of the Uniled Shalts Covemment ot the Univatity of Calitornis, and whall not be uted for advertiaing or product endoriement purposes.

\author{
Jrsiled in the Unitrd States of Amerisd \\ Awallake: Irom

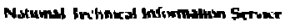

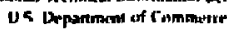

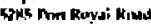

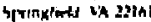

Price

Code

A01

\section{Papercopy Price:}

A02

$A 03$

AO4

A05

AOS

A07

A0s

A09
Page

Range

Microfiche
001-050

051- 100

$101-200$

201-300

$301-400$

401-500

$501-600$

601 


\section{INTRODUCTION}

\section{DE89 008643}

Since June 1974, the MFE Computer Center has been engaged in a significant computational physics effort. The principal objective of the Computational Physics Group is to develop advanced numerical models for the investigation of plasma phenomena and the simulation of present and future magnetic confinement devices. Another major objective of the group is to develop efficient algorithms and programoing techriques for current and future generations of supercomputers. In addition, the group Interacts with the systems programing staff to improve services; it fills the roles of internal critic and advisor by representing a user viewpoint. Moreover, many of the group's computer codes employ state-of-the-art algorithms that use and test the prototypical hardware and software features of the new machines; these codes have played a major role in perfecting the software supplied by KHFECC.

The group currencly consists of six Ph,D, physicist/ mathematicians - D.V. Anderson, G.D. Kerbel, A.E. Koniges, M.G. McCoy, A.A. Mirin and D.E. Shumaker. In addition, students (currently numbering 4) in the Department of Applied Science (u.C. Davis) are engaged in fusion regearch under the guidance of senior group members.

The computational physics group has been Involved in several ereas of fusion research. One main area is the application of Fokker-Planck/qussilinear codes to tokamaks. Another major area is the Investigation of resistive magnetohydrodynamics in three dimensions, with applications to tokamaks and compact toroids, A third area is the investigation of kinetic instabilities using a 3-D particle code; this work is often coupled with the task of numerically generating equilibria which model experimental devices. Ways to apply statistical closure approximations to study tokamak-edge plasma turbulence have been under examination, with the hope of being able to explain anomalous transport. Also, we are collaborating in an international effort to evaluate fully three-dimensional IInear stability of toroidal devices. In addition to these computational physics studies, the group has developed a number of linear systems solvers for general classes of physics problems and has been making a major effort at ascertaining how to efflciently utilize multiprocessor computers.

One of the principal objectives of the computational physics group is to provide support for experimental and theoretical work within the MFE combunity. At present, this support falls into the following areas:

RF heating and current drive in tokamaks

GA, ORNL, PPPL, MIT ANPC, LLNL, Culham Varennes (Quebec)

Fokker-Planck/transport analyses of tokamaks ILNL

Tokamak equilibrium and stability U.C. Davis

Compact torus transport/equilibrlum/stability LANL

MHD evolution of Spheromak and FRC LANL, LINL, Spectra

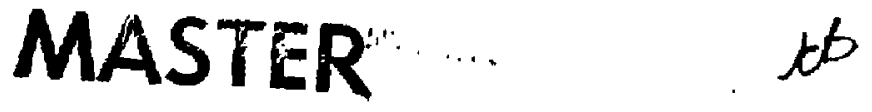


Turbulence models in plasma physics

Direct matrix solvers/3-D equilibrium and stability calculations

A summary of our program follows.
PPPL, LLNL, UCSD

Ecole Polytechnique Federale de Lausanje

II. COMPUTATIONAL STUDIES

\section{A. EQUILIBRIA AND STABILITY}

\section{TIME INDEPENDENT MODELS}

In simple 1-D configurations the calculation of plasma equilibrium profiles is rather trivial. For more realistic two and three dimensional plasmas, the determination of the equilibrlum magnetic flelds and the plasma pressure is a complicated nonlinear problem involving the solution of elliptic partial differential equations. One of the goals of this work is to obtain configurations like those seen in experiments; accordingly some of our calculations use boundaries and external coll sets which accurately represent the devices under study. A secondary goal is to compute equilibria of sufficient accuracy so that the results can be used by stability codes with some confidence. In this connection high order finite element or finite difference representations have been used. These equilibria are also used to explore single particle effects in equilibrium wagnetic flelds.

Most of our codes solve Ampere's lat given some nonlinear dependence of the currents on the fields. Other codes use a dynamic evolutionary approach with artificial damping to obtain steady flow equilibria. Still others merely numerically evaluate known analytical equilibrium profiles. Several of these codes are briefly described in Table 1 .

Our research has been in the following areas:

- A code was developed to solve the 2D MHD equilibrium problem for compact torolds. The algorithm is applicable to elongated plasmas. Fintte elements are used to solve the Grad-Shafranov equation. The region in which the equilibriur is computed may contain a separatrix, and plasma may be present both inside and outside of the separatrix. The equilibrium is determined from adiabatic quantifles, magnetic fluxes and entropy; hence, the solver is suitable for insertion in transport code. This code has been documented and made available to the fusion community.

-A 2D klnetic equilibrium code for compact torolds has recentiy been developed. The distribution functions depend on the Hamiltonian and the canomical angular momentum; the electrostatic potantial is obtained from quasineutraltty. The code can also compute zero-electron-temperature equilibria; In this case the electrostatic potential is an input quaneity. 
- Tandem mirror equilibriun calculations have been undertaken in 3D, with the goal of making the simulations as realistic as possthle. A multispectes plasma is modeled in a multi-region conflguration to account for the varfous types of trapped and passing components known to exist in these devices. Ambipolar effects are fncluded. High beta and finite curvature effects are modeled without making low beta or long-thin approxirations. A finite element representation is used on a rectangular grid. The effect of sheath formation has been shown to be in agreement with other theory and experiments. Some species, such as sloshing lons, are prorly represented by adhoc pressure functions, so these are being supplemented by models using correct moments of microscopic distribution functions. Comparison with models using the paraxial approximation have been carried out. It appears that the long-thin approximation is not valid for most realistic mirror configurations.

-A code which computes the yacuum magnetic field Inside a toroidal vessel of arbitrary cross-section was developed and applied to HELIAC. General curvilinear coordinaces conforming to the shape of the vessel are used. The magnetic scalar potential is expanded as a double Fourier series in the poloidal and toroidal angles. The resulting magnetic fields have been evaluated for their minimum-average-B and shear stability properties using the field line tracing code TUBE. The aim has been to find optimum vessel configurations by calculating the resulting surface currents and later discretizing these skin currents with closed current loops.

- The three dimensional stability of three dimensional toroidal ideal MHD equilibrla is beling addressed in a new code, TERPSICHORE, being built as a collaborative effort between ourselves and European colleagues in Germany and Switzerland. Rather general stellarator and tokamak configurations are representable in this code which uses finite Fourier series to parameterize each closed toroldal flux tube. Assuming the validity of the given equilibrium configurations, the code can be used to determine stability limits, second stability regions, and optimal coll specifications.

Our time-independent equilibria and stability publications are summarized in Appendix Al.

\section{TIME DEPENDENT MAGNETOHYDRODYNAMICS}

A principal technique for determining macroscopic plasma behavior is through the solution of the time dependent MHD equations. Of parcleular interest is the nonlinear evolution and saturation of fluid instabilities. Accurate simulation of such phenomena requires the solution of the full set of MHD equations. which comprises a coupled system of eight nonlinear partial differential equations. This is a formidable task for any computer system. In order to make these computations tractable. approximations have often been made, including reduction in 
dimensionality, linearization, restriction to a particular geometry and the assumptions of infinite conductivity and/or low "beta" ("beta" is the ratio of plasma pressure to magnet1c pressure). The tnfinite conductivity assumption (called ideal MHD) greatly simplifies the numerics, since the MHD equations are then hyperbolic rather than parabolic. Moreover, resistive MHD instabilftles tend to grow more slowly than ideal MHD instabilities, thereby requiring longer running times, the low beta assumption allows an ordering in which the problem is reduced to the solution of two scalar equations.

At the MFECC, the emphasis has been on constructing resiscive MHD codes which are applicable to all plasmas, Both linear and nonlinear codes have been written which solve the full set of resistive, "finite-beta" MHD equations in two and three dimensions (see Table 2). Moreover, most of these codes use an implicit time discretization, so that there is no restrictive non-physical upper bound on the size of the timestep.

Our MHD research has been in the following areas:

- Llnear studies of resistive interehange modes in the reversed fleld pinch were carried out using a two-fluid code. These simulations included Hall terms and tensor thermal conductivities and viscosities. It was shown that Hall and electron thermal conduction effects together (but neither alone) would provide stabilization.

-A 30 nonifnear, resistive, inftial-value, compressible code has been used to model a cylindrical reversed field pinch. In one application, this code, along with four other 3D codes (developed at other institutions), has simulated an identical problem to try to ascertain the effects of compressibility in RFP dynamics. The study showed that compressibility could be instrumental in determining field reversal malntenance.

- Our nonlinear 3D code has been applied to the behevior of resistive modes in a spheromak. Whether or not a general equilibrium relaxes to a force free state, and if it does, how long it takes and how the relaxation is affected by MHD modes. has been under Investigation. The effects of hall terms are Included.

The nonlinear 3D code described above has been modifled to include implicit differencing. For the purposes of economizing computer time, a multitasked semi-implicit technique has been implemented. Hall terms are also treated semi-implicitly. Implicit simulations of the spheromak have been carried out, with a fartor of $\mathbf{3 0}$ savings in computer time. Studies have recently been under way to analyze the effectiveness of the semi-implicit method for simulations with Hall cerms. Toward this afm, calculationii relevant to spheromak, FRC, and RFP scenarlos have been carried out. 
- Inveatigations have begun into the possibility of fueling a tokamak reactor such at ITER through the injection of compact toroids (GT's). It is believed that such a technique may be necessary since conventional fueling methods may not be adequate for deep penetration. One of the critical issues with such a scheme is magnetic reconnection, for tt plays a major role in determining where and when the fuel is deposited. Our present calculations start with a $C T$ being placed at rest in a uniform magnetic field modified to exclude the CT. Prelininary results show the or tilting in roughly an Alfven time as its internal structure decomposes.

- A study of the stability of long, thin theta-pinch equilibria to the $n=1$ tilt mode was undertaken, Earlier numerical work predicting a fast growing tilt instabllity was in contradiction to the long quiescent $t$ imes of the experiments. The hypothesis that the computations were based on incorrect models of the theta pinch equilibrtum is now refuted, Usage of a resistive MHD stability code has shown that stretching of the closed elliptical flux surfaces (making them more racetrack as in the experiments) Is destebilizing. The stability of these devices to chis mode is due to effects beyond the MHD model. In particular, kinetic effects must be taken into consideration.

Our time-dependent MHD publications are summarized in Appendix A2.

\section{B. PLASHA TRANSPORT}

Transport codes are used to evaluate macroscopic plasma parametera (e.g. density, temperature) on a timescale comparable to the lifetime of the plasma. They differ frow other fluid codes In chat the fast cimescale physics is integrated out of the problem.

At the MFECC, transport codes have been applied to tokamaks, compact toroids and tandem mirrors. A list of our transport codes and their applications appears in Teble 3 .

Over the past years we have made a great deal of progress in the following areas:

- Fokker-Planck/transport studies of tokamaks

- Anomalous electron transport in tokamaks

- Transport in compact torolds

-Radial transport in tandem mirrors

We have also been looklag into plasma turbulence as an explanation for anomalous transport (see section F).

A brief summary follows. 
- Fokker-Planck/Transport Studies of Neutral Beam-Heated Tokamaks

Neutral beam-heated tokamaks are character:-ed by the presence of one or more energetic ion species wich are quite non-Maxwelifan along with a warm Maxwellian bulk plasma. For scenarios th which there is a large energetic ion population, is 1s very importan. to represent these energetic species by means of velocley space distribution functions and to follow their evolution In time by integrating the Fokker-Planck equations. It is essential to utilize the full nonlinear Fokker-Planck operator to assure that the slowing down and scattering of these energetic species is computed accurately and realistically.

Our Folker-Planck/transport code (FPT), in addition to solving radial transport equations for the bulk plasma densities and temperatures, solves nonlinear Fokker-Planck equations in 2D velocity space for the energetic ion distribution functions. The FPT code is unlque in that it is the only tokamak transport code which does not either linearize the Fokker-Planck operator or Ignore it altogether. Also, neutral beam deposition and neucral cransport are computed using appended Honte Carlo codes developed at Princeton.

During the last decade FPT has been applied to a number of experiments. Host recently it has been used to model TFTR and ITER. The TFTR simlations have concentrated an ascertalning the beam-beam, beam-target and thermonuclear fusion rates; excellent agreement with the "supershot" results is obtained. The ITER simulations have concentrated on evaluating che effectiveness of neutral beam current drive; efficiencies comparable to those of $r f$ schemes are obtained.

-Anomalous Electron Transport in Tokamaks

Over the years, there has been considerable interest in the effects of anomalous electron transport due in part to magnetic surface destruction. Since this heat loss represents a major problem In torotdal confinement, there has been a need for a prcgram which would simulate this loss and allow for credible estimates of the effects of electron cransport on lower hybrid heating, D.C. conductivity and soft $x$-ray spectra.

The computer program (LDL) which has consequently been developed is $2-D$ and has as independent variables velocity magnitude and radial position. It combines a velocity and radially dependent heat source and a 1 -D Fokkex-Planck treatment of electron collisions wth a lass operator simulating diffusion in velocity-radius. This program has been applied to the Doublet experiments at GA Technologies, Inc. 
-Transport in Compact Toroids

The compact rorus experiments (field reversed theta pinch and spheromaks) differ from the tokamak in that the plasme extends to the axis of rotational symmetry. Interest in the compact torus is due to the fact that it is 1 ikely to attain high beta and the fact that there is an engineering advancage of not having any structure through the center of the torus.

A transport code, CTT, has been writcen to describe the evolution of the plasma and magnetic field in a compact torus, This code differs from the tokamak transport codes in that the plasma extends to the axis of rotational symmetry and the 2-D equilibrium calculation contains a separatrix. The system evolves by elternating between the solution of four 1-D transport equations and the calculation of a 2-D equilibrium. The independent varlable is the poloidal magnetic flux. Classical diffusion, Pfirsch-Schluter diffusion, radiation, Joule heating, lower hybrid drift diffusion and open fleld line loss are modeled.

The code has been used to model the FRX and the css experiments. In the former case good agreement with the experiment is obtained provided the coli.ision frequencies are appropriately enhanced; discrepancles elong the open field Ines, however, point to the need for 2D modeling in that region.

- Radial Transport in Tandem Mirrors

A tandem mirror machine consista of a long, solenoidal cell with minimum-B mirrors (plugs) at either end which act to electrostacically confine the central cell lons. The rate at which charged particles and heat diffuse in radius is of crucial importance. Of special significance is the expecte's enhanced transport of lons due to resonance between their azimuthal drift and axial bounce motions, which results from the presence of a non-axisymetric magnetic field in the transition regions between the end plugs and the solenoid. A radial transport code, THT, was written in order to investigate this and other related phenomena. This multispecies code computes radial profiles of densities and temperatures in both the central solenold and the end plugs along with a self-consisterit electric fleld. Classical and neoclassical effects on transport are caken into account. This code has been used to study the Tanden Mirror Experiment and to help design larger tandem ofirror devices.

Our transport publfcations are summarized in Appendix B.

\section{FOKKER-PLANCK}

The Fokker-Planck equation is needed to treat plasmas in which the charged particle velocity space distribution functions axe non-Kaxwelilan. In a magnetic mirror device, charged 
particles will tend to laak out the ends of the device, resulting in a "loss cone" in velocity space. In devices where there is neutral bean injection, rf heating or a large d.c. electric field, the ion distribution functions will be characterized by an energetic component (in addition to the Maxwellian background). These are situations which require the use of Fokker-Planck codes.

The MFECC has led the nation in the development and implementation of multispecies Fokker-Planck codes employing the complete nonlinear two-dimensional Fokker-Planck operator. Since our codes have heen generalized to deal with toroidal and openended configurations, many physical effects have been incorporated in then and a variety of physical problens have been studied. A summaxy of our Fokker-Planck codes appears in Table 4.

\section{Progress has been made in the following areas:}

- We developed a user-ortented package, FPPAC, which computes the coefficlents of the uniform-field nonlinear 2D velocity-space Fokker-Planck collision operator and time-integrates the corresponding finice difference equations. The user may specify additional physit:s terms and rather arbitrary boundary conditions. FPPAC has been made avallable to the MFE community.

- A nonlinear multispecies Fokker-Planck code (CQL) whlch bounce-averages the differential operators of Coulomb collistons, quasilinear resonant diffision induced by wave-particle Interaction and an Ohmic electric field has been developed. A zero banana width is assumed, CQL is designed primarily to simulate toroidal devices, although it can be utillzed for mirror applieations. The relativistic collieinal cuefficients incorporate an arbitrary number of terms in the Legendre expansion of the distribution functions. The $\mathrm{rf}$ operator incorporates mass shift, spectral and collisional resonance broadening and models waves ot the electron cyclotron, ion cyclotron and lower hybrid frequencies. CQL has recently been put in package form and relensed to the MFE community.

- To obtain a global view of tokanak operation, the two dimenstonal $(u, \theta)$ code CQL described above has incorporated a three dimensional module, together called CQL3D, which allows the calculation to proceed at several radial mesh points simultaneously. Due to the bounce averaging, the resulting picture 1s, In most cases, actually four dimensional, if one considers the pololdal perspective. The 3D version is well suited to Ioplementation in a maltitasking environment since the distribution functions at the various radial meshpoints are advanced Independently. A wave damping calculation to compute electric flelds and other relevent wave parameters as a function of position (radial and poloidal) provides linkage between the radial meshpoints. CQL3D is intended for use primarily on the Cray 2 . 
- A number of studies have been undertaken with the CQL famfly. In collaboration with G.A., fusion reactivity enhancement by ICRF has been examined; at high $Q$ the enhancement factor ranges from 1.3 to 2.0. A more recent application of the code examines the relative merjts of Inside vs. outside launch schemes for ECH current drise, with particular attention to relativistic effects. The CQL study advises an outside launch, which Is contrary to what is currently being done in D3D. Present efforts include (1) a coupling of CQL3D to the GA transport code ONETWO and the Princeton/Oak Ridge neutral beam code FFREYA; this will allow global simulation of tokamak performance and the determination of neutxal beam current drive efficlency in devices such as ITER; this has ircluded generalizing CQL to accept noncircular cross-sections; (2) coordination between the full wave propagation calculations for ICRH and ray optics calculations for ECRH and the consequent quasilinear development of the underlying distributions; (3) the use of CQL to evaluate linear growth rates and saturated wave amplitudes for beam-driven instabilities; and (4) relaxation of the zero-banana-width reseriction to allow the calculation of non-Maxwellian corrections to neoclasalcal transport coefficlents (applicable to alpha, neutral beam, and rf heated plasmas .

- Tanded Mirror Applications

A study of electrostatically trapped elictrons in a tandem mirror thermal barrier has recently been completed. This has required solving Fokker-plarck equations for trapped electrons in the presence of passing electrons and under the influence of electron cyclotron resonant heating.

Calculations of fuston performance in D-D tandem mirrors have also been completed. Fokker-Planck equations for deuterons and the four reaction products have been solved. Radiation losses, recycling and drift pumping for ash removal have been included. Some p-baged calculations have also been carried out.

A 20 nonlinear multispecles code has been used to assess trapping rates of passing lons in tanden mirror end cells. A scaling law valid over a wide range of mircor ratio, trapping parameter and potential-to-temperature ratio has been developed.

Our Fokker-Planck publications are sumarlzed in Appendix C.

\section{PARTICLE AND VIASOV MODELS}

-Three-Dimensional Particle Code

A 3-D quasi-neutral hybrid particle-in-cell codo which models ions as particles and electrons as massless, zeta-temperature fluid has been developed for the cray-2. Unlike earlier partıcle codes tiset required disk memory a"id scalar 
interpolation, tedlous coding of buffered disk memory and the corresponding waste of CPU time have been ellminated and new algorithms which allow every phase of the calculation of be vectorlzed and multitasked have been developed. The Interpolation between the grid and the partieles has been coded in terms of indirect indices and executes in vector mode via the hardware gather and scatter instructions. An optimized particle sorting scheme consistent with vectorization has been developed. The ffelds are computed on a cylindrical grid in such a way as to guarantee a solenoldal magnetic fleid. The vacuum region is modeled as a resistive medium. Studies of Field Reversed Configurations have been undertaken. As a benchmark, the rotational instabllity of the rigld rotor was modeled and found to agree with a 2D particle code; for this purpose a special treatment of the low density regions had to be incorporated. The code has recently been applied to a study of the nonlinear evolution of the tilt mode instability in a FRC. It is shown that in the large gyroradius limit kinetic effects stabilize the mode. The growth rates axe in fair agreement with linear calculations using a kinetic model. Simulations into the nonlinear regime are being undertaken.

- We have written a code called ORB which solves the equations of motion assoclated with Littlejohn's guiding center Haniltonian theory for tokamak geometry. Included are several model wave field excitations for studying wave-particle interaction in three dimensions. The code includes a facility for representing the orbit in terms of 1 ts (slowly varying) first order instantaneous constants of motion. To do this, the current state of motion is Interpreted through the zeruth order Hamiltonian to get the corresponding adiabadic invarfants. ORB is used in conjunction vith our bounce-averaged Fokker-Planck code CQL3D and is an important ingredient of our transport effort.

-A self-consistent guiding center particle model coupled with a fluid equilibrium code was used to study ion beam motion in a toroidal geometry. Applications include the study of collisionless beam behavior in the case of strong counterstreaming beams and the steady state modeling of a cIT reactor, in which beam currents and energy reinfection rates are computed.

- A single particle orbit following code was used to make detailed studies of the confinement properties of equilibrium flelds in two and three dimensions, Scudies of adiabaticlty as well as resonant orbital effects were made. Experimentalists used the code to design ion probe diagnostics.

- A one-dimensional Vlasov finite difference code for lons and electrons was written to study the formation of a plasma sheath and to compute steady state distribution functions along with a plasma potential.

Publications in this area are listed in Appendix D. 


\section{E. EFFICIENT NUMERICAL ALGORITHMS AND PROGRAMMING TECHNIQUES}

- Solution of Sparse Implicit Systems

A general study of Preconditioned Conjugate Gradient Methods for solving sparse 1 inear systems is being carried out. This technique has been shown to ba considerably faster than other traditional linear solvers such as SOR and ADI. Solvers applicable to both scalar and vector $2 D$ and $3 D$ operators have been written and made available to the MFE community. These solvers incorporate (as an option) the biconjugate gradient (BCG) method. BCG tends to converge faster than ordinary CG and is more amenable to multitasking. A multitasked form of the BCG solvers is available. The use of vectorized indirect indexing has made it possible to produce packages applicable to various mesh stencils and sparsity patterns with a minimum of effort. In this connection a fully Inplicit Naxwell's equation solver in which the various field components are closely coupled has been built and tested. Our sparse matrix solvers, which are listed in Table 5, have been'are being published to provide adequate documencation and allow easy access by nther users.

Performance measurements of our solvers for coupled IDE's shows a degradation in computing speed by a factor of four from what could be obtained using assembly language. Even with assembly code, there is stili constderable raom for improvenent: both from the standpoints of parallelization and convergence rates. Based on some recent successes on related problems, we are investigating the properties of preconditioners based upon incomplete watrix inversion.

-Solution of Block-Banded Systems

In some applications the structure of the resulting matrix systen 1s block tridiagonal with dense blocks. This kind of structure arises from the use of spectral representations in one or wore of the coordinate directions. We have developed a new code, RAMS, that solves this type of system. PAYS has been designed to exploit the three forms of parallelism available on the Cray-2 - multitasking, vectorlzation and functional unit overlap. Speeds in excess of 1.2 Gflops have been meastred, thus making PAMS one of the fastest codes available on the Cray-2. PaMS has also been used as a benchrazk for vector supercomputers. It has been tested on the Cray-X/MP, Cray-2, Fujftsu VP-200, NEC SX-2, CDC-205, and the ETA-10 Piper. It has been extended to solve more general block multidiagonal systems and is part of an eigensolver in a 3-D stabillty code.

Multitasking

The CRAY-XMP and CRAY-2 computers possess more than one CPU and hence have the capability of parallel computation. Computer codes that require large fractions of the central memory or that need fast real time performance can benefit if they are written such that parallel computation is feaslble. This mode of 
calculation is referred to as multitasking in the CRAY environment. The computational physics group is investigating the efficient utilization of the CRAY-2 in this direction. Some of our multitasking applications have been discussed $I n$ the above section on sparse marrix solvers. A brief summary of our ather multitasking applications follows.

-The VEPEC code, which computes 30 tandem rilrror plasma equilibria (see Table 1), has been used as a test bed for studying multitasking in the crss environment. The 1dea here has been $=0$ ascertain the extent to which existing codes can be converted to multitasking without too much rewriting. The efficient multitasking of a vectorized 3D ADI solver appropriate for certain nonlinear problems has been demonstrated. This shows the perhaps unexpected value of miltitasking even for tightly coupled implicit systems. Another important issue is the cost of the overhead required to implement multitasking - this is closely related to the granularity of the tasks, A further objective has been to provide feedback as to the design of the operating system, where in fact VEPEC experfence led to a new system scheduler that gives greatly 1mproved multttasking performance.

- Dur multitasked simulation code (SIMU) uses the concept of ensemble averaging to solve a prototyplcal three-wave interaction problem. The use of ensemble averaging, as opposed to time-averaging, turns the problem into an ideal cancidate for multitasking. Since reallzations of the dynumical equation can he grouped into arbltrary-sized packets, the multitasking nature of the code cin be adapted for machines with arbitrary numbers of process: $r s$ - from four to four thousand. In order to run SIMU and gui rantee reproducible results Inciependent of the multitasking, we require a means of producing strings of random numbers for each process. This problem is very fmportant in all Monte-Carlo calculations run on multiprocessor computers. We have devised a method for producing independent strings based on hopping through a random number sequence at large intervals and picking up a seed for each process. This method is particulariy useful for our application and shows promise for use in general Monte Carlo codes.

-Another Important issue is the degree of multiprocessing efficiency one should expect to get under CTSS, which is an intense time-sharing environment. In thls regard we have used our 3-D MHD code TEKCO to study multitasking performance as a function of task size and code fleld length. This has led to a theoretical model designed to predict the multiprocessing performance under cTSS. This model shows, for example, that (assuming the time to get an additional processor is $6 \mathrm{~ms}$ ) a multitasing job must have a fleld length of at least 10 Mwds if an overlap factor of 3.5 is to be attained. We have found In genersi that the CTSS scheduler allows good overlap provided the code 15 large and the task string (i.e. the set 
of tasks which are available to rut: consecutively on a processor) is of medium-to-large granulerity.

- The previously mentioned TERPSICHORE code is an example of a new code developed from scratch with multitasking designed Into it. We used the PAMS algorithm as a basic component of the code's eigenvalue solver. Moreover, it has been found that the large arrays of flux tube integrals required to determine the matrix operator coefficients may be rapidly computed from matrix-matrix products that are trivially multitaskable. A construct testing this idea has run at speeds of up to 1.73 Gflops on our new static memory Cray-2. This is presently being installed in the TERPSICHORE code.

Our multitasking codes are sumnarized in Table 6.

Publications in efficient numerical algorithms and programming techniques are summarized in Appendix E,

\section{F. PLASHa tURBULENCE aNd aNOHALOUS TRANSPORT}

Strong turbulence is a leading candidate to explain anomalous transport in tokamak plasmas. Only theorfes whleh incorporate fully nonlinear effects of strong turbulence have the potential for predicting the large anomalous transport coefficlents belived present in modem devices. The primary means of studying strong turbulence include analytic predictions, turbulence closure models, and direct simulation. The following are areas in which we are active.

- Ensemble Averaging

The most fundamental way to simulate turbulent phenomena is to time-advance the nonlinear equations and average over $a$ Gaussian ensemble of initial conditions. Although this is not a practical means for describing complex systems, applying it to simple systems provides considerable insight into the relevant statistical dynamics. He have written a multitasked 3-wave simulation code for the purpose of studying plasma-type systems which contain inherent driving and damping. Such systems are fundamentally different from the viscous Navier-stokes equations, which require external forcing to achieve steady states. We have used this code to study the drift wave system. The primary results show that certain assumptions such as the decay of correlacion functions and the applicability of a fluctuation-dissipation relation can be used in some (but not a.1) situations.

-Two-Poinc Closures

In principle, turbulence closures can provide a theoretical understanding as well as predictions of turbulent flow properties. We are developing a program aimed at Investigating the feasibility of two-point closures for complex calculations. In particular, we are considering new algorithms to accelerate 
$-14$.

numerical computation of the class of closures typiffed by Kraichnen's Direct Interaction Approximation (DIA). We are developing a closure theory which $1 \mathrm{~s}$ both applicable to plasma turbulence and amenable to numertcal solution. Approximations based on the physics of the turbulent steady state are potentially useful for simplifying the numerical computation. Is particular, we have used numerical simulation to show that the fluctuation-dissipation relation is a reasonable approximation for damped/driven system in steady state. Our current scheme incorpozates this approximation, and in doing so, eliminates a costly integration present in full DIA calculations. Finally, we are invest1gating a procedure based on Pade approximates which simplifles the probiem further. Additionally, this method elimiates the need for the introduction of ad hoc parameters (usually based on estimates of the eddy viscosity) In models of the Markovian type.

\section{-Applications to Multifield Systems}

Anelytic investigation of tokamak turbulence evolution equations has implied that even a minimal dynamical description of drift wave turbulence requires two-field evolution equations for the density and potential functions. We are plenning to study the equilibrium statistical mechanics of the two-field hasegawa-Wakatant model of drift wave turbulence. Additionally, we will examine the Importance of the cross-correlation spectrum which has been traditlonally neglected in Markovian closure calculations for fluid dynamic applications. We seek to quantify notions of a nonlinear transfer rate in terms of entropy production, and to verify analytic estimates of relaxation spectra.

\section{f. OTHER AREAS}

We have undertaken some projects in ocher areas, as follows:

-Convergent Neutral Beams

A study was made involving the creation of a very dense plasma by injecting convergent neurral bsaps into spherical or cylindrical chambers. Calculations of particle distribution functions, densities, Ionization rate parameters and ionization probabllities were carrled out for toth geometries.

Publications in these areas are summarized in Appendix $G$. Miscellaneous publications are listed in Appendix $H$. 
TABLE 1. MFECC TIME INDEPENDENT CODES

\begin{tabular}{|c|c|c|}
\hline CODE & CONTACT & CHARACTERISTICS AND APPLICATIONS \\
\hline CYLEQ & D.V. ANDERSON & $\begin{array}{l}20(R, Z) \text {, Bicubic Splines, Finfte } \\
\text { Element, Tensor Pressure; } \\
\text { Tandem Mirrors, Compact Toroids }\end{array}$ \\
\hline VEPEC & D.V. ANDERSON & $\begin{array}{l}\text { 3D }(X, Y, Z) \text {, Tricubic Splines, } \\
\text { Finite Element, Vector Potential, } \\
\text { Tensor Pressure, Ambipolar EfEect, Vlasov Species } \\
\text { Tandem Mirrors }\end{array}$ \\
\hline ABCXYZ, TPSIC & D.V. ANDERSON & Auxiliary codes for VEPEC \\
\hline HILLSV & D.V. ANDERSON & Auxiliary code for CYLEQ \\
\hline EIV & D.E. SHUMAKER & $\begin{array}{l}\text { 2D, Flux Coordinates, Finite Elements, } \\
\text { Open and Closed Field Lines: } \\
\text { Compact Toroids }\end{array}$ \\
\hline EQV & D.E. SHUMAKER & $\begin{array}{l}\text { 2D, Kinetic Equilibria, Flux Coordinates, Finite } \\
\text { Elements, Open and Closed Field Lines; Compact } \\
\text { Torolds }\end{array}$ \\
\hline VAFIS & A.I. SHESTAKOV* & $\begin{array}{l}\text { 3D, Louble Fourier Series, General } \\
\text { Coordinates; Stellaratars, HELIAC }\end{array}$ \\
\hline TUBE & A.A. MIRIN & Field Line Tracing Code; General Magnetic fields \\
\hline STABCRIT & D.V. ANDERSON & $\begin{array}{l}\text { 2D (R, Z) Ballooning Modes, Energy } \\
\text { Principle }\end{array}$ \\
\hline TERPSICHORE & D.V. ANDERSON & $\begin{array}{l}\text { 3D Displacements of 3D Toroidal } \\
\text { Equilibria; Tokameks, Stellarators }\end{array}$ \\
\hline
\end{tabular}

*Currently in CP-Division (LLNL) 
TABLE 2. MFECC TIME DEPENDENT MHD CODES

CODE

CONTACT

CHARACTERISTICS AND APPLICATIONS

TEMCO

A.A. MIRIN

3D $(R, \phi, Z)$, Nonlinear, Sera-Implicit, Resisl: $y$. Fourier Expansion in $\phi$, Viscous, Hall terms; Compact Toroids, RFP

RIPPLE VI

A. I. SHESTAKOV* 2D (R,Z), Linear, Nonaxisymmetric Perturbations, Implicit, Resistive: Compact Toroids

ALIMO

A. I. SHESTAKOV* 2D $(R, Z)$, Linear, Axisymmetric Perturbations, Impllate, Resistive;

Compact Toroids

RIPPLE V

A.I. SHESTAKOV* 1D $(y)$, Linear, Impliclt, Equilibrium Flow

RIPPLE IV

A. I. Shestakov* 1D (r), Linear, Implicit, Resistive; Tokamaks, RFP

ODRIC

A.A. MIRIN

1D (r), Linear, Implielt, Resistive, Compressible, Tensor Viscosity, Tensor Thermal Conductivity.

Hall terms, Two-Fluld; Tokamaks, RFP

*Currently in CP.Division (LLNL) 
TABLE 3. MFECC TRANSPORT CODES

\begin{tabular}{|c|c|c|}
\hline CODE & CONTACT & CHARACTERISTICS AND APPLICATIONS \\
\hline TMT & A.A. MIRIN & 1D (R); Tandem Mirrors \\
\hline FPT & A.A. MIRIN & $\begin{array}{l}\text { Combined Fokker-Planck/Transport, } \\
\text { ID (A) plus 2D }(\mathrm{V}, \theta) \text {; Tokamaks }\end{array}$ \\
\hline CTT & D.E. SHUMAKER & $\begin{array}{l}\text { 1D (Polaldal Flux)/2D Equilibrium; Compact } \\
\text { Toroids }\end{array}$ \\
\hline TRANSPORT & A.A MIRIN & 1D (R); Tokamaks \\
\hline LDL & M.G. MeCOY & $\begin{array}{l}\text { 2D (H,V); Electron Transport; } \\
\text { Tokamaks }\end{array}$ \\
\hline
\end{tabular}


TABLE 4. MFECC FOKKER-PLANCK CODES

\begin{tabular}{|c|c|c|}
\hline CODE & CONTACT & CHARACTERISTICS AND APPLICATIONS \\
\hline HYBRID II & A.A. MIRIN & $\begin{array}{l}\text { 2D }(V, \theta) \text {, Jonlinear, } \\
\text { Multispecies Ions; } \\
\text { Mirrors and Tokamaks }\end{array}$ \\
\hline TDHFP & A.A. MIRIN & $\begin{array}{l}\text { 2D }(\mathrm{V}, \theta) \text {, Nonlinear, } \\
\text { Multispecies Lons } \\
\text { and Electrons; Mirrors }\end{array}$ \\
\hline TDMSZ & A.A. MIRIN & $\begin{array}{l}\text { 3D }(\nabla, \theta, Z) \text {, Nonlinear. } \\
\text { Multisper:ies Ions } \\
\text { and Electrons }\end{array}$ \\
\hline FPPAC & $\begin{array}{l}\text { H.G. MeCOY } \\
\text { A.A. MIRIN }\end{array}$ & $\begin{array}{l}\text { 2D }(V, \theta) \text {, Nonlinear, } \\
\text { Multispecies Ions; } \\
\text { General Package }\end{array}$ \\
\hline ISOTIONS & A.A. MIRIN & $\begin{array}{l}\text { ID (V), Nonlinear, } \\
\text { Multispectes Ions } \\
\text { and Electrons; } \\
\text { Mfrrors and Tokamaks }\end{array}$ \\
\hline CQL & $\begin{array}{l}\text { M.G. MeCOY } \\
\text { G.D. KERBEL }\end{array}$ & $\begin{array}{l}\text { 2D }(v, \theta) \text {, Nonlinear, Bounce } \\
\text { Average, Multispecies Ions, Quasilinear rf } \\
\text { Relativistic, Noncircular Cross-sections; } \\
\text { Tokamaks }\end{array}$ \\
\hline CQL3D & M.G. KoCOY & $\begin{array}{l}\text { 3D ( } r, v, 6) \text {, Nonlinear, Bounce } \\
\text { Average, Multispecies Ions } \\
\text { and Electrons, RF with } \\
\text { Wave Damping, Relativistic, Noncircular } \\
\text { Cross-sections; Tokamaks }\end{array}$ \\
\hline RFT & G.D. KERBEL & $\begin{array}{l}\text { Trajectory Integral Propugator and } \\
\text { Data Base Generator for CQL }\end{array}$ \\
\hline $\mathrm{ORB}$ & G.D. KERBEL & $\begin{array}{l}\text { Guiding Center Hamiltonian Orbit } \\
\text { Code used in Conjunction with CQL }\end{array}$ \\
\hline
\end{tabular}


TABLE 5, MFECC ITERATIVE MATRIX SOLVERS

$\begin{array}{lll}\text { CODE } & \text { CONTACT } & \text { PURPOSE } \\ \text { ICCG2 } & \text { D.V. ANDERSOH } & \text { 2D Symmetric, Scalar } \\ \text { ICCG3 } & \text { D.V. ANDERSON } & \text { 3D Symmetric, Scalar } \\ \text { ILUCG2 } & \text { D.V. ANDERSON } & \text { 2D Asymmetric, Scalar } \\ \text { ILUCG3 } & \text { D.V. ANDERSON } & \text { 3D Asymmetric, Scalar } \\ \text { ILUBCG2 } & \text { A.E. KONIGES } & \text { 2D Asymetric, Scalar } \\ \text { CPDES2 } & \text { D.V. ANDERSON } & \text { 2D Asymetric, Vector } \\ \text { CPDES3 } & \text { D.V. ANDERSON } & \text { 3D Asymmetric, Vector } \\ \text { MTBCG2 } & \text { A.E. KONIGES } & \text { 2D Asymmetric, Scalar } \\ \text { MTCS2 } & \text { A.E. KONIGES } & \text { 2D Asymmetric, Vector } \\ \text { MTCS3 } & \text { A.E. KONIGES } & \text { 3D Asymmetric, Vector } \\ \text { ILUBCG2 - 11 } & \text { A.E. KONIGES } & \text { 2D 11-Banded }\end{array}$


TABLE 6, MFECC MULTITASKING CODES

$\begin{array}{lll}\text { CODE } & \text { CONTACT } & \text { PURPOSE } \\ \text { VEPEC } & \text { D.V. ANDERSON } & \text { Plasma Equilibria } \\ \begin{array}{l}\text { MTBCG2 } \\ \text { MTCS2 } \\ \text { MTCS3 }\end{array} & \text { A.E. KONIGES } & \text { Iterat I ve Matrix Solvers } \\ \begin{array}{l}\text { QN3D } \\ \text { RQC }\end{array} & \text { D.E. SHUMAKER } & \text { Particle Code } \\ \text { SIMU } & \text { A.E. KONIGES } & \text { Turbulence } \\ \text { PAMS } & \text { D.V. ANDERSON } & \text { Direct Matrix Solver } \\ \text { TEMCO } & \text { A.A. MIRIN } & \text { MHD Evolution/Stability } \\ \text { TERPSICHORE } & \text { D.V. ANDERSON } & \text { MHD Stab11ity }\end{array}$


Appendix Al - Time Independent Equilibria and Stabllity References Papers and Invited Talks

R.P. Frels, C.W. Hartman, J. Killeen, A.A. Mirin and M.F. Uman, "Calculations of Combined Steilarator-Multipole Toroldal Megnetic Field Configurations," Nucl. Fusion 17. No. 2 (1977), 281.

D.v. Anderson and D.C. Barnes, "Accurate Calculations of Fleld-Reversed Axtsymmetric Equilibxia and their wHD Stability Properties," J. Comput. Phys. 42 (1981), 288.

D.V. Anderson, J. Breazeal and C.B. Sharp, "Calculations of 3D Mirror Equilibria using a Finite Element Vector Potential Representation," J. Comput. Phys. 46 (1982), 189 ,

D.S. Harned, D.W. Hewett, C.G. LIIllequist, R.W. Moses, D.D. Schnack, J.L. Schwarzmeier, A.G. Sgro, R.L. Spencer, D.V. Anderson, J. KItleen, A.A. MIrIn, N.J. O'Ne111, A.I. Shestakov, D.E. Shumaker, S.P. Auerbach, J.K. Boyd, T.A. Brengle, B.I. Cohen, J.H. Hammer, C.W. Hartman,

W.C. Turner, A. Aydemir, D.C. Barnes, C. Bernard, W.M. Tang, C. Seyler and J. Tataronis, "Compact Toroidel Plasnas: Simulations and Theory," NInth Int'1. Conf. on Plasme Physics and Controlled Nuclear Fusion Research, Balt1more (19B2), (IAEA, Vienra), II, 293.

A.I. Shestakov and A.A. Mirin, "A Fourlex Method for 3-Dimensional Partial Differential Equations--Application; HELTAC,"J. Conput. Phys. 56 (1984), 469.

D.E. Shumaker, "Numerical Calculation of Compact Torus Equilibrium," J. Comput. Phys. 53 (1984), 456 .

A.I. Shestakov, "Application of the Implielc Double Fourier Expansion Hethod co 3-D1mensional Equilibrla," Second European Workshop an Computational Problens in the Calculation of MHD Equilibria," Wildhaus, swltzerland (1983), Comput. Phys. Commun. 31 (1984), 227.

D.V. Anderson, "Non-Ideal Equilibria: Calculations of Amblpolar and Magnetostatic Confinement in Tanden Mirrors," Second European Workshop on Computational Problems in the Calculation of MHD Equilibria," Wildhaus, Switzerland (1983), Comput. Phys. Rpts. 1 (1984), 427.

D.V. Anderson and H.E. Rensink, "Self-Consistent. Three-Dimenstonal, Electrostatic and Magnetostatic Tandem Mirror Equilibria," Phys. Fluics 27 (1984), 322.

A.E. Konfges and J.L. Johnson, "A Helical Axls Stellarator Equllibrium Kodel," Phys. Fluids 28 (1985), 3127.

A.1. Shestakov and A.A. MLrin, "Design of HeLIAC Vacuum Magnetic Flelds," Nucl. Fuston 25 (1985), 681 .

D.E. Shumaker. "Numerical Calculation of Equlltbrium for the Fleld-Reversed Configuration," Fusion Tech. $\underline{9}(1986), 75$.

D.E. Shumaker, "EIV: Axisymmetric Plasma Equilibrium Code," Comput. Phys. Comaun. 44 (1987), 177. 
A.A. Mirin, D.R. Martin and N.J. O'Neill, "TUBE88: A Code which Computes Hagnetis Field Lines," to appear in Comput. Phys. Commun.

D.V. Anderson, A. Cooper, R. Gcuber and U. Schwenn, "Linear MaHD Stability Analysls of Toroldal 3D Equllibria," Jolnt Varenna-Lausanne Int'1. Workshop on the Theory of Fusion Plasmas, Chexbres, Switzerland (1988), to appear in Nuovo cimento.

Reports, Extended Abstracts and Invited Seminars

C.H. FInan, III, "LAFCO76-Magnetic Field Code," UCRL-51804 (1975).

C.H. Finan, III, and B. McNamara, "MAFJ-Some SImple Additions to MAFCO," UCRL-51806 (1975).

R.P. Freis, G.W. Hartman, J. K1llean, A.A. Mirin and M.F. Uman, "Numerical Studies of Toroldal Magnetic Fleld Configurations," UCRL-78041 (1976).

A.A. Mirin, M.F. Uman, C.W. Hartman and J. Killeen, "An Analytic Representation of Fields Regulting from Currents on a Torus," UCRL-52069 (1976) .

D.V. Anderson, J. Breazes1, C.H. FInan and B.H. Johnston, "ABCXYZ: Vector Potential (A) and Magnetic Fleld (B) Code (C) for Cartesian (XYZ) Geometry using General Current Elewents," UCRL-52029 (2976).

J.C. Taylor and J.V. Taylor, "ELIPTI-TORHAC: A Code for the Solution of General Non-1inear Elliptic Problems over 2-D Reglons of Arbftrary Shape," Proc. 2nd IMACS Int'1. Symposium on Computer Methods for Paxtial Differential Equations, Bethlehem (1977).

J.C. Taylor and J.V. Taylor, "The Elipti Code-Part 1," UCRL-79328 (1977).

B.v. Anderson, J, Breazeal and C.B. Sharp, "VEPEC: A 3D vector Potential Equilibrium Code for High Beta Minimun-B Plaswa Confinement, " UCRL-53099 (1981).

D.V. Arderson, J.H. Hanmer and D.C. Barnes, "The Analytical and Numerical Calculations of Fleld Reversed Theta Pinch Equilibria Based on a Generalized Hill's Vortex Model, "Fourth Symp. on the Physics and Technology of Compact Torolds, Livermore (1981), UCRL-86B31.

A.I. Shestakov and A.A. Mirin, "Computation of the Vacuum Magnetic Field in a Heliac Geometry," Proc. ThIrd Stellarator Study Warkshop (New York, 1982), 331 .

A.I. Shestakov and A.A. Mirin, "Computation of the Vacuum Magnetic Field In a Hellac Geonetry," Eourth Int'1. Stellarator Workshop (Cape May, 1982).

A.I. Shestakov and A.A. Mirin, "A Fouriar Method to Solve 3-D Problems in Hellac Geometry." Tenth Conf, on the Numertcal Simulation of Plasmas, San Dlego (1983), 2 CL2.

A.I. Shestakov, A.A. Mirin and N.J. O'Ne1ll, "Searching for Modular Coils In HELIAC," Fourth U,S. Stellarator Workshop, Oak RIdge (1983). 
A.E. Koniges, "Equilibrium Studies for Asperator NP-3,4 Using a Helical Axis Stellarator Expansion," Fifth U.S. Stellarator Workshop, Madison (1984).

A.I. Shestakov, "A Fourier Method to Calculace the Vacuua Magnetis Fleld in Toroldal Geometry," UCRL-90629 (1984).

\section{Conference Abstracts}

C.G, Tull, D.V. Anderson and J.H. Foote, "Equilibrium Adiabaticity and Confinement Time Studies for Minimum-B Mirror Devices," Bull, Am, Phys. Soc, 19, 921 (1974); Albuquerque.

M.G. MeCoy, M.E. Rensink, A.A. Mirin and J. Killeen, "The Role of Equilibria in Noncircular Transport Calculations, " Annual Controlled Fusion Theory Conf, Gatlinburg (1978), D2.

D.V. Anderson and J.H. Hammer, "On the Existence of S11t and Very Rectangular Equilibria in Reversed Field Theta Pinches," Annual Controlled Fusion Theory Conf., Austin (1981), 2 C11.

D.V. Anderson, J. Killeen, T.B. Kalser and M.E. Rensink, "2D and 3D Computations of Guiding Center Equilibria for Tandem Mirrors including Ambipolar Effects," Bull. Am. Phys. Soc. 26, 1006 (1981); New York.

A.I. Shestakov and A.A. Mirin, "Computation of the Vacuun Magnetic Field in a Heliac Geometry," Annual Controlled Fusion Theory Conf., Santa Fe (1982), $2 \mathrm{E} 37$.

D.v. Anderson, "A 3-D Model for Computing Self-Consistent Transport Dominated Tandem Mirror Equilibria," Annual Controlled Fusion Theory Conf., Santa Fe (1982), 2E12.

A.A. Mirin and A.I, Shestakov, "Vacuum Magnetic Fleld Solver in a Hellac Goometry," Bull, Am. Phys. Soc. 27, 1023 (1982). New Orleans.

D.V. Anderson, "Tandem Mirror Equilibria with Cur ature Effects," Bull, Aro. Phys, Soc, 27, 911 (1982), New Orleans.

A.I. Shestakov, A.A. MIxin and N.J. O'Meill, "Modular Coil Design and Magnetic Surfeces in Heliac," Annual Controlled Fusion Theory Conf., Arlington (1983), 2R14.

D.V. Anderson and M.E. Rensink, "3D Calculations of Seif-Consistent Electrostatic and Magnetostatic Equilibria in Tandem Afirors," Annual Controlled Fusion Theory Conf., Arlington (1.983), 1P8.

M.J. O'NeI11, A.I. Shestakov and A.A. Hirin, "Numerical Search for Optimum HELIAC Configurations," Bull. Am. Phys. Soc. 28, 1074 (1983); Los Angeles.

A.I. Shestakov, "An Efficient Method to Calculate the Vacuum Fleld in an Axisymmerric Torus," Bull. Am. Phys. Soc. 28, 1124 (1983); Los Angeles.

D.V. Anderson, "The Existence of Sheaths in Tandem Mirror I11br"a," Bull. Am, Phys, Soc. 28, 1185 (1983); Los Angeless 
D.V. Anderson and B.M. Boghosian, "Electrostatic and Magnetostatic Tandem Mirror Equilibrla from Realistic Plasma Distributions," Annual Controlled Fusion Theory Conf, , Lake Tahoe (1984), 1s20.

A.I. Shestakov and A.A. Mirin, "Calculation of HELIAC Vacuum Magnetic Field Configurations," Annual Controlled Fuston Theory Conf., lake Tahoe (1984). 2R1.

A.I. Shestakov and A.A. Hirin, "Computer Design of Modular Goils for HELIAC," Bull. Am. Phys. Soc. 29 (Boston, 1984), 1273.

D.V. Anderson and B. Lane, "Numerical Studies of Finite Beta Equilibria in the Constance Mirror Experiment," Bull. Am. Phys. Soc. 29 (Boston, 1984). 1270 .

A.E. Koniges and J.L. Johnson, "A Hellcal Axis Stellarator Equilibrium Mode1," Bull. Am. Phys. Soc. 29 (Boston, 1984), 1273.

D.V. Anderson and B. Lane, "Investigations of Long-Thin M1rror Equilibria with the Full 3-D Method as Cosputed by VEPEC," Annual Controlled Fusion Theory Meet1ng, Madison (1985), 1R27.

D.E. Shumaker, "Nunerical Simulatiri, of Equilibria and Transport in a Field-Reversed Configuration," Bull. All. Phys. Soc. 30 (San Dlego, 1985).

D.E. Shumaker, "Calculation of 2-D Axisyometric Vlasov Equilibrium for a Fleld-Reversed Conflguration Plasma," Bull. Am. Phys. Soc. 31 (Balt imore, 1986), 1607.

D.V. Anderson and B. Lane, "Comparisons of Single Cell Minimum-B Mirror Equilibria in the Paraxial Limit," Bull. An. Phys. Soc. 31 (Baltimore, 1986), 1622.

D.E. Shumaker, D.Q. Hweng and S.C. Jardin, "Equilibrium and Stability of the Davis Diverted Toksmak," Annual Controlled Fusion Theory Conf., San Diego (1987). 1C14.

D. Flittner, R. Bradley, J. DeGrout, T. Hillyer, D.Q. Hwang, K. Hizuno, G. Dimonte and D.E. Shumaker, "Design and Initial Operation of the Davis Diverted Tokamak," Bull. An. Phys. Soc. 32 (San Diego, 1987), 1905.

D.V. Anderson, A. Cooper, R. Gruber and $v$. Schwenn, "TERPSICHORF Code: Linear MHD Stabilicy Analysis of 3D Equilibria," Bull. Amer. Phys. Soc. 33 Hollywood (1988), 1928. 
Appendix A2 - Time-Dependent MHD References

\section{Papers and Invited Talks}

J.A. Dibiase, J. Killeen, D.C. Robinson and D. Schnack, "Linear and Non-Linear Calculation of the Tearing Mode in Reversed Field Pinches, "In Pulsed High Beta Plasmas (Pergamon Press, Oxford, 1976), 283.

J.A. Diblese and J. Killeen, "A Numerical Model for Resistive

Magnetohydrodynamic Instabilities," J. Comput. Phys. 24 (1977), 158.

J. Killeen and A.I. Shestakov, "Effect of Equilibrium Flow on the Resistive Tearing Mode," Phys. Fluids 21 (1978), 1746.

D.D. Schnack and J. Killeen, "Linear and Non-Linear Calculations of the Tearing Mode, " in Theoretical and Computational Plasma Physics (IAEA, Vienra, 1978), 337 .

D.D. Schnack and J. Killeen, "Non-Linear Saturation of the Tearing Mode in a Reversed Field Pinch," Nucl. Fusion 19 (1979), 877.

J. Killeen, D.D. Schnack, and A.I. Shestakov, "Linear and Non-Linear Calculations of Resistive Magnetohydrodynamic Instabilitles," In Computing Methods in Applied Science and Engineering, (North Holland, Arsterdam, 1980), 305.

D.D. Schnack and J. Killeen, "Non-Linear Two-Dimensional

Magnetohydrodynamic Calculations," J. Comput. Phys. $\underline{35}$ (1980), 110.

D.A. Baker, C.J. Buchenauer, L.C. Burkhardt, T.E. Cayton, E.J. Caramana,

G.I. Chandler, R.S. Christian, R. Dagazian, J.N. DiMarco, J.N. Downing,

J.P. Freidberg, R.F. Gribble, R.A. Gerwin, D.W. Hewetc, R. B. Howe 21,

A.R. Jacobson, F,C, Jahoda, J. Killeen, K.A. Klare, H, R. Lewis,

E.M. Little, L.W. Mann, G. Miller, R.W. Moses, R.A. Nebel, S. Ortolani,

R.B. Paris, J.A. Phillips, D.D. Schnack, A.E. Schofield, K.S. Thomas,

R.G. Watt, P.G. Weber, J.A. Wesson, R. Wilkins, and Y. Yoshida, "Initial

Reversed-Field Pinch Experiments on ZT-40 and Recent Advances in RFP

Theory." Eighth Int'1. Conf. on Plasma Physics and Controlled Nuclear

Fusion Research, Brussels (1980), (IAEA, Vienna), II, 291.

W.T. Armstrong, D.C. Barnes, R.R. Bartsch, R.J. Comnisso, C.A. Ekdahl, I. Henins, D.W. Hewe Ct, H.W. Hoida, T.R. Jarboe, C.G. Lilliequist, R.K. Linford, J. Lipson, J. Marshal1, K.F. McKenna, J.P. Mondt, D.A. Plates, C.E. Seyler, A.R. Sherwood, E.G. Sherwood, R.E. Siemon, D.V. Anderson, R. Christian, E.H. Klevans, S. Hamasaki, D.D. Schnack, J.M. Sayer, A.I. Shestakov, and J. Killeen, "Compact Toroid Experiments and Theory," Eighth Int'l. Conf. on Plasma Physics and Controlled Nuclear Fusion Research, Brussels (19B0), (IAE.A, Vienna), I, 481. 
D.V. Anderson, S.P. Auerbach, H.L. Berk, J.K. Boyd, T.A. Brengle, J.A. Byers, B.I. Cohen, W.C. Condit, J.C. Eddleman, R.P. Freis, E.H.A. Granneman, J.H. Hammer G.H, Hartman, J, Killeen, B. McNamara, W.A. Newcomb, L.D. Pearlstein, M.G. McCoy, D.S. Prono, J.M. Sayer. D.D. Schnack, D.E. Shumaker, J.W. Shearer, A.C. Smith, J. Taska, W.C. Turner, D.E. Drlemeyer, G.H. Mley, E.C. Morse, E. McColl and H. Weitzner, "Theory of Field-Reversed Mirrors and Field-Reversed PIasma-Cun

Experiments," Elghth Int'1. Conf. on Plasma Physics and Controlled Nuclear Fusion Research, Brussels (1980). (IAEA, Vienna) I, 469.

D.D. Schnack, J. Killeen, and R.A. Gerwin, "The Jon-Linear Evolution of Resistive Interchange Hodes in Reversed-Field Pinches," Nuc1, Fuston 21 (1981), 1447 .

D.C. Barnes and D.V. Anderson, "Long-Wavelength MHD Stability of the Field Reversed Theta Pinch," Phys. Rev. Letters 46 (1981), 1337.

C.H. Finan, III and J. Killeen, "Solution of the Time-Dependent, Three-Dimensional Resistive Magnetohydrodynamic Equations," Comput. Phys. Commun. 24 (1981), 441 .

G.D. Kerbel, "The Gyroelastic Screwpinch," Phys. Fluids 25 (1982), 306.

A.I. Shestakov, J, K11leen and D.D. Schnack, "A Numerical Model for Non-Axisymetric MHD Instabilitles," J. Coapur. Phys, 46 (1982), 69.

D.S. Harned, D.W. Hewett, C.G. Lilliequist, R.W. Hoses, D.D. Schnack, J.L. Schwarzmeier, A.G. Sgro, R.L. Spencer, D.V. Anderson, J. Killeen, A.A. MirIn, N.J. O'Nel11, A.I. Shestakov, D.E. Shumaker, S.P. Auerbach, J.K. Boyd, T.A. Brengle, B.I. Cohen, J.H. Hamer, C.W. Hartwan, W.C. Turner, A.Y. Ayderir, D.C. Barnes, C. Bernard, W.M. Tang, C. Seyler and J. Tataronis, "Compact Toroldal Plasmas, Simulations and Theory," Ninth Int'1. Conf. on Plasma Physics and Controlled Nuclear Fusion Research, Baltimore (1982), (IAEA, Vienna), II, 293.

J.L. Schwarzmeler, D.C. Barnes, D.W. Hewett, C.E. Seyler, A.I, Shestakov, and R.L. Spencer, Magnetohydrodynamie Equilibriun and stablitty of Field Reversed Configurations," phys. Fluids. 26 (1983), 1295.

T.R. Jarboe, C.W. Barnes, I. Henins, H.W. Hoida, S.O. Knox, D.A. Platts, A.R. Sherwood. B.L. Wright, G.J. Marklin, A.G. Sgro, R.X. Linford, A.A. Mirin and D.E. Shumaker, "Spheromak Studies on CTX," Tenth Int' 1 . Conf. on Plasma Physics and Controlled Nuclear Fusion Research, London (1984), (IAEA, Vienna) II, 501.

A.Y. Aydemir, D.C. Barnes, E.J. Caramana, A.A. Mirin, R.A. Nebel, D.D. Schnack and A,G. Sgro, "Compresslblifty as a Feature of Fleld Reversal Malntenance in the Reversed Field Pinch," Phys. Fluids 28 (1925), 898.

A.A. Mirin, N.J. O'Neill, J, Killeen, R.J, Bonugli and M.J. Ellis, "Linear Studies of Resistive Interchange Modes in a Cylindrical keversed Field Pinch," Phys. Fluids. 29 (1986). 512.

A.A. Mirin, R.J. Bonugli, N.J. O'Neill and J. Killeen, "ODRIE, One-Dimensional Linear Resistive MHD Gode in Cylindrleal Geometry." Comput. Phys. Commun. 41 (1986). 85. 
A.A. Mirin, "The Question of Consistent Boundary Conditions when Simulatin!; Reversed Field Pinch Dynamics," Phys. Fluids 29 (1986), 3018.

R,Y. Dagazian, J.P. Dahlburg, G. Doolen, C, Marklin, A.A. Mirin, J.P. Mondt, D. Montgomery, A.G. Sgro, L. Turner and J. Weiland, "Evolution, Relaxation and Transport in Spheromaks and Reversed Field Pinches," Eleventh Int'1. Conf. on Plasma Physics and Controlled Nuclear Fusion Research, Tokyo (1986), IAEA, Vienna, II, 639.

A.G. Sgro, A.A. Mirin and G. Marklin, "The Evolution of a Low Beta Decaying Spheromak," Phys. Fluids 30 (1987), 3219.

C.W. Hartman, W.L. Barr, J.L. Eddleman, M. Gee, J.H. Hammer, S.K. Ho, B.G. Logan, D.J. Meeker, A.A. Mirin, W.M. Nevins, L.J. Perkins,

D.E. Shumaker, A. Leonard, P.B. Parks, H. Mclean, E. Morse and D.R. Solvin, "Acceleration of Compact Toroid Plasma Rings for Fusion Applications," Twelfth Int' 1 . Conf. on Plasma Physics and Controlled Nuclear Fuston Research, Nice (1988), IAEA-CN-50/H-1-11.

Reports, Extended Abstracts and Invited Seminars

D.D. Schnack, "Non-Iinear Numerical Studies of the Tearing Mode," UGRL-52399 (1977)

D.D. Schnack and J. Killeen, "Non-Linear Saturation of the Tearing Mode in a Reversed Field Pinch," Reversed Field Pinch Workshop, Padua (1978), UCRL- 81218 .

J. Killeen, D.D. Schnack, and A.I. Shestakov, "Linear Calculation of Resistive Instabilities in Reversed Field Pinches," Reversed Field Pinch Workshop, Padua (1978), UCRL-81266.

C.H. Finan and D.D. Schnack, Mulcldimensional Magnetohydrodynamics Calculations," IEEE Int'1. Conf. on Plasma Science, Monterey (1978), 6B3.

D.D. Schnack and J. Killeen, "General Non-linear Two-Dimensional HHD Calculations," Eighth Conf. on the Numerical Simulation of Plasmas, Monterey (1978), PA-5.

C.H. Finan and J. Killeen, "IMP-A 3 Dimensional, Non-linear Resistive Implicit MHD Program," Eighth Conf. on the Nunerical Simulation of Plasmas, Monterey (1978), OA-3.

A.I. Shestakov, D.D. Schnack, and J. Killeen, "The Tilting Mode in the Reversed-Field Theta Pinch," U.S.-Japan Joint Symposium an Compact Toruses and Energetic Particle Injection, Princeton (1979), UCRL-83698.

H.L. Berk, J. Sayer, and D.D. Schnack, "Tearing Mode Stability Analysis of a Cylindrical Plasma," U.S.-Japan Joint Symposium on Compact Toruses and Energetic Particle Injection, Princeton (1979), UCRL-93504.

C.H. Finan, "Three-Dimensional MHD Calculatious," 1979 IEEE Int"I. Conf. on Plasina Science, Montreal (1979), 304

D.D. Schnack and J. Killeen, "Nonlinear studies of Resistive Interchange Instabilities in a Reversed Field Pinch," 1979 IEEE Int"1. Conf. on Plasma Science. Mantreal (1979), 5B2. 
D.D. Schnack, "Dynamical Determinstion of Ohmic States of a Cylindrical P1nch," Proc. RFP Theory Workshop, Los Alamos (1980), UCRL.84202.

D.D. Schnack and J. Killeen, "The Nonlinear Evolucion of Resistive Interchange Modes in a Reversed Field Pinch." Proc. RFP Theory Workshop. Los Alamos (1980), UCRL-8430i.

D.C. Barnes, A.Y. AydemiI, D.V. Anderson, A.I. Shestakov and D.D. Schmuct: "Inear and Non-linear Computations of the Ideal MHD Tilting Mode in the FRX-B Configuration," Third Symp. on the Physics and Technology of Compiat Toroids, Los Alamos (1980), UCRL-85131.

A.I. Shestakov, D.D. Schnack and J, Killeen, "Ripple VI and Alimo-Two-Dimensional Linearized Resistive MHD Stability Codes, "Ninth Conf. on the Numerical Simulation of Plasmas, Evanston $:(980)$. OA-f.

D.V. Anderson, H.L. Berk and J.H. Hammer, "Ballooning Mode Growth Rate Dependence on Separatrix Shape for Idealized Equilibria of a field Reversed Theta Pinch," Third Symp, on the Physics and Technology of Compact Toroidi. Los Alamos (1980), UCRL-B5130.

J. Killeen, "A Review of the Time-Dependent, Three-Dimensional Resistive Magnetohydrodynamic Calculations," Proc. US-Japan Theory Workshop on 3-D MHD Studies for Toroidal Devices, Oak Ridge (1981), 98.

G.D. Kerbe1, "Gyroelastic Fluids," UCRL-53101 (1981).

A.I. Shestakov and N.J. O'Neill, "Resistive MHD Stabllity Calculations of Force-Free Spheromak Configurations," Fourth Symp. on the Physics and Technology of Compact Toroids, Livermore (1981), UCRL-86813.

J. Killeen, "A Review of Time-Depeadent. Three-Dimensional, Resistive: MHD Calculations, " 1hth AINSE Plaswa Physics Conf, Lucas Helghts, Ausi ralia (1983).

A.A. Mirin and J. Killeen, "Nonlinear Three-Dimensional MHD Calculations of Resistive Instabilfties in a Reversed Field Pinch." U.S. Japan Workshop on 3-D MHD SLudies for Magnetically Confined Plasmas, Nagoya (1983).

D.C. Robinson, J.A. Dibiase, A.S. Furzer, J. Killeen and J.E. Nunn-Price, "The Growth of Resistive Instabilities in a Diffuse Pinch," UKAEA Report No. CLM-P710, Culham Laboratory (1983).

A.G. SgYo, G. Marklin and A.A. Mirin, "Transport, Stabillty and Relaxation of a Spheromak," US-Japan Sympostum on Compact Toroid Research, Princeton $(1984)$.

A.A. Mirin, N.J. O'Neill and A.G. Sgro, "Nonlinear MHD Simulations of the Reversed Field Pinch," US-Japan Workshop on 3-D MHD Studies for Toroidal Devices, Oak Ridge (1984).

A.A. Mirin and A.G. Sgro, "Multimode Fvolution of the Decaying, Spheroinak," Proc. Seventh CT Symposium, Santa lis (1985).

A.A. Mirin and A.G. Sgro, "Nonlintar MHD Evo?ution of the CTX Spheroinak." Eleventh Int'1. Conf, on the Numprical Simujatjon of Plasmas, Mont real (1985), 2B10. 
A.A. Mirin and A.G. Sgro. "Applications of TEMCo to the Spheromak and the Reversed Field Pinch," U.S.-Japan Workshop on 3-D MHD Studies, Oak Ridge (1986).

A.G. Sgro, A.A. Mirin and G. Marklin, "Theory of the Evolution of a Decaylng Spheromak," U.S.-Japan Workshop on Compact Toroid Research, Kyoto (1986).

A.A. Mirin and A.G. Sgro, "Semi-Implicit Resistive MHD Simuliions of a Decaying Spheromak," Eighth U.s. Compact Toroid Symosium, College Park (1987).

A.A. Mirin and A.G. Sgro, "MHD Simularions of Hall Term Effects in a Decaying Spheromak," Twelfth Conf. on the Numerical Simulation of Plasmas, San Francisco (1987), PW19.

\section{Conference Abstracts}

D.D. Schnack, J. Killeen, and C. Finan, "Nonlinear Evolution of the Tearing Mode in a Sheet Pinch," Bull. Am. Phys. Soc. 20, 1311 (1975);

St. Pecersburg.

D.D. Schnack, Jr, and J. Killeen, "The Non-Linear Tearing Mode,"

Bul1. Am. Phys. Soc, 21. 1133 (1976); San Francisco.

D.D. Schnack and J. Killeen, "Linear and Non-Linear Numerical Studies of Resistive Instabilities in Cylindrical Geometry, "Annual Controlled Fusion Theory Conf., San Diego (1977), Al7.

C.H. Finan and J. K1lleen, "3D Non-Linear Evolution of the Internal Kink Mode in a Resfstive Plasma," Annual Controlled Fusion Theory Conf., San Diego (1977), A6.

C.H. Finan and $J$. Kflleen, "NonI inear Internal MHD Modes in 3-D Resistive Plasmas," Bull. Art. Phys. Soc. 22, 1154 (1977); Atlanta.

A.I. Shestakov and J. Killeen, "The Effect of Equilibrium Flow on the Resistive Tearing Mode," Bull. Am. Phys. Soc. 22, 1156 (1977); Atlanta.

D.D. Schnack and J. Killeen, "Growth and Saturation of the Tearing Mode in a Reversed Fleld Pinch," Bull. Am, Phys. Soc. 22, 1156 (1977): Atlanta,

J. Killeen and D.D. Schnack. "Non-Linear Saturation of the Tearing Mode," Bu11. Am. Phys. Soc. 22, 1155 (1977); Atlanta.

D.D. Schnack and J. Killeen, "Nonlinear Evolution of Resistive Interchange Modes in a Reversed Field Pinch," Annual Controlled Fusion Theory Conf., Gatlinburg (1978), A25.

D.D. Schnack and J. Killeen, "Nonlinear Numerical Computations of Resistive Interchange Modes in a Reversed Field Pinch," Bull. Am. Phys, Soc. 23, 831 (1978): Colorado Springs.

A 1. Shestakov, J. Killeen. and D.D. Schnack. "Linear Calculations of Tlaring Modes in High-Beta Toroidal Equilibria," Bull. Am. Phys. Soc. 23. 830 (1978): Colorado Springs. 
C.H. Finan and J. Killeen, "3-D Resistive MHD Computations." Bul1. Am. Phys. Soc. 23, 831 (1978); Colorado Springs.

D.D. Schnack and J. Killeen. "The Nonlinear Evolution of Resistive Instabilitles in Finfte-Beta Reversed Field Pinches," Annual Controlled Fusion Theory Conf., Mount Pocono (1979), 3B31.

J. KIlleen, A.I. Shestakov, and D.D. Schnack, "2-D Linear Resistive MHD Calculations," Bull. Am. Phys. Soc. 24. 952 (1979): Boston.

A.I. Shestakov and $J$. Killeen. "Axisymmetrlc Linearized Resistive MHD Calculations," Bull. Am. Phys. Soc, 24, 95? (1979); Boston.

D.D. Schnack and J. Killeen, "Nonlinear Resistive Calculations for Reversed Fleld Plnches," Bull. Am. Phys, Soc - 24, 1023, (1979): Boston.

C.H. Finan, J. Killeen, and D.D. Schnack, "Three Dimensional Simulation of Spontaneous Field Reversa1," Bull. Am. Phys. Soc. 24, 1024 (1979); Bostan.

J.M. Sayer, D.D. Schnack, and A.I. Shestakov, "Resistive Calculations for the Reversed-Field Theia Pinch," Bull. Am. Phys. Soc. 24, 1081 (1979); Boston.

J.M. Sayer, D.D. Schnack and H.L. Berk, "Tearing Mode Stability of a Long-Thin Reversed-Field Theta Pinch," Annual Controlled Fusion Theory Conf., Tucson (1980), 2B24.

D.D Schnack, "Dynamical Determination of Ohmic States of a Cylindrical Pinch," Annual Controlled Fusion Theory Conf., Tucson (1980), 2A5.

Y. LI and D.D. Schnack, "Simulation of the Formation Phase of Spheromak." Annual Controlled Fuslon Theory Conf.. Tucson (1980), 1C25.

A.I. Shestakov, D.D. Schnack and J, Killeen, "Numerical Study of Low Toroidal Mode Number Instability in a Compact Torus," Annual Controlled Fusion Theory Conf., Tucson (1980), $2 \mathrm{B1}$.

A.I. Shestakov, C. Chandler, D. Nguyen and J, Killeen, "Resistive MHD Calculations for Tokamaks with Elongated Cross Sections," Bul1. Am. Phys. Soc. 25, 847 (1980); San Diego.

D.V. Anderson, H.L. Berk and J.H. Jammer, "MHD Growth Rate Dependence on Separarrix Shape of a Fleld Reversed Theta Pinch", Bull. Am. Phys. Soc. 25 . 884 (1980); San Diego.

D.D. Schnack and D.W. Hewett, "Particle and Fluid simulations of the $m=0$ g-Mode." Bul1. Am. Phys. Soc. 25, 1024 (1980); San Dlego.

D.C. Barnes, A.Y. Aydemir, D.V. Anderson and D.D. Schnack, "Nonlinear Sinulation of the Ideal MHD Tllting Mode in a Prolate Field Reversed Configuration," Bull. Am. Phys. Soc. 25, 884 (1980); San Diego.

R.Y. Dagazian and D.D. Schnack, "Helical Ohmic States for Reversed Field P1nches," Bull. Am. Phys. Soc. 25, 865 (1980); San Diego. 
A.I. Shestakov and J. K1lleen, "Calculation of Non-Axjsymetric MHD Instabilities in Toroidal Plasmas wich D-Cross Sectlons, "Annual Controlled Fusion Theory Conf., Austin (1981), 2B45.

G.D. Kerbel and W.A. Newcomb. "Gyroelastic Fluids," Annual Controlled Fusion Theory Conf., Austin (19B1), $2 B 31$.

N.J. O'Neill, A.I. Shestakov and A.A. Mirin, "The Effects of Small Ampl:tude Mid Instablities on Magnetic Field Topology." Annual Controlled Fusion Theory Conf., Austin (1981), 2C23.

A.A. Hirin and A.I. Shestakov, "Preliminary Results of a 3-D Nonlinear Resistive MHD Code," Bull. An. Phys. Soc. 26, 956 (1981): New York.

A.I. Shestakov and N.J, O'NeI11, "Linear Resistive Stability Studies for Spheromak Equilibria," Bull. Am. Phys. Soc. 26, 8B2 (1981); New York.

J. Killeen and A.A. Mirin, "Nonlinear 3-D Simulations of Resistive Interchange Modes in a Reversed Field Pinch," Bull. Am. Phys. Soc. 27, 941 (1982); New Orleans.

A.I. Shestakov, "Influence of Elliptical vs. Racetrack FRTP Equilibria on the n- 1 Tilring Mode," Bull. Am. Phys. Soc, 27, 1213 (1982); New Orleans.

A.A. Mirin and N.J. O'Neill, "Linear and Nonlinear Studies of Resistive Interchange modes in a Reversed Field Pinch." Annual Controlled Fusion Theory Conf., Arlington (1983), 2P7.

A.A. Mirin and N.J. O'Ne111, "Modeling of Resistive g-Modes in a RFP," Bull. Am. Phys. Soc. 28, 1186 (1983); Los Angeles.

G. Marklin, A.G. Sgro and A.A. Mirin, "Transport and Relaxation in a Spheromak," Bull, AIn. Phys. Soc. 2B, 1215 (1983); Los Angeles.

A.G. Sgro, G. Marklin and A.A. Mirin. "Simulation of the Evolution of a Spheronak," Annual Controlled Fusion Theory Conf., Lake Tahoe (1984), 1 P13.

A.A. Mirin and N.J. O'Ne111, "The Effect of Hall Terms on Resistive g-Modes in a Reversed FieId Pinch." Annual Controiled Fusion Theory Conf.. Lake Tahoe (1984), 1Q2.

A.A. Mirin, R.J. Bonugli and M.J. Ellis, "Computational Study of Resistive Interchange Modes in a Reversed Field Pinch," Bull. Am. Phys. Soc. 29 (Boston, 1984), 1375 .

A.G. Sgro, G. Marklin and A.A. Mirin, "Evolution of Finite Beta Spheromaks," Bull. Am. Phys. Soc. 29 (Boston, 1984), 1242.

A.Y. Aydemir, D.C, Barnes, E.J. Garamana, A.A. Mirin, R.A. Mebel, D.D. Schnack and A,G. SEro, "MHD Compressibility and the Reversed Field Pinch," APS Plasma Physics Division Meeting (Boston, 1984), submiteed in liru of paper $7 \mathrm{R} 2$.

A.A. Mirin and A.C. Sgro, "Nonlinear MHD Seudies of the CTX Spheronak," Alnual Contralled Fusion Theory Meting. Madison (1985), 2 S10 
A.G. Sgro, G. Mark1in and A.A. MLrin, "The Evolutjon of a Spheromist for Different Resistivity Profiles," Annual Controlled Fusion Theory Mroring; Madison (1985), 3Q14.

R.A. Nebel, A.A. Mirin. D.D. Schnack and E.J. Caramana. "Hall Ef foe' in $3-!$ Nonlinear MHD Simulations for the RFP," Bull. Am. Phys. Soc. 30 (San Dicpo. 1985), 1401 .

A.G. Sgro and A.A. Mirin, "Influence of Hall Effects on a Decaying Spheromek and PreIiminary Simulations of the Sustained Spheromak."

Bull. Ar. Phys. Soc. 30 (San Diego, 1985), 1452.

A.A. Mirin, "The Issues of Boundary Conditions and Time Discretization whe StmulatIng MHD Dynamics," Annual Controlled Fusion Theory Meeting, Nis Yor: (1986), 3C40.

A.A. Mirin, "Semi-Implicit Resistive MHD Calculations In a Toroidal Domain," Bull. Am. Phys. Soc. 31 (Baltimore, 1986), 1562.

A.G. Sgro and A.A. Mirin, "Resistive MHD Simulations with Hall Terns of a Decay1ng Spheromak," Bull. Aua. Phys. Soc, 32 (San Diego, 1987), 1736.

D.E. Shumaker. A.A. Mirin, E.J. Horowitz and D.A. Callahan, "Simulation of the Tilt Mode in the FRC." Bull. Am. Phys. Soc. 32 (San Diego, 1987), 177.

D.E. Shuroaker, A.A. Mirin and J.H. Hamer, "MHD Simulation of Tokamak Fueling by the Injection of Compact Torolds," Annual Controlled Fusion Theory Conf., Gatlinburg (1988), 3C25.

A.A. Mirin and A.G. Sgro, "Status Report of MHD Simulations with Hall Jer!ns / Discussion of Rotation in a Spheromak." Bull. Am. Phys. Soc. 33 (Hollywood, 1988), 1926. 
Appendix B - Transport References

\section{Papers and Invited Talks}

D.E. Shumaker and 1.B. Bernstein. "Improved Variational Method for Axisymmetric Plasmas," Phys. Fluids $\underline{18}$ (1975), 1487.

M.L. Watkins, M.H. Hughes, K.V. Roberts, P.M. Keeping and J. Killeen, "ICARUS-A One-Dimenstonal Plasma Diffusion Code," In Methods in Computational Physics 16 (1976). Academic Press, New York, 166.

D.L. Jassby, R.M. Kulsrud, F.W. Perkins, J. K1lleen, K.D. Marx, M, G. McCoy, A.A. Mirin, M.E. Rensink and C.G. Tul1, "Counterstreaming-Ion Tokamak Fusion Reactors," Sixth Intl. Conf., on Plasma Physics and Controlled Nuc lear Fusion Research, Berchtesgaden, FRG. 1976), (IAEA, Vienna) Ii, 435.

A.A. Mirin, J. Killeen, K.D. Marx and M.E. Rensink, "A Radial Transport/Fokker-Planck Model for a Tokamak Plasma," J. Comput. Phys. 23, No. 1 (1977), 23.

D.E. Post, R.J. Goldston, R.C. Grimm, R.J. Hawryluk, S.P. Hírshman, D. Hsieh, R.A. Hulse, D.L. Jassby, R.V. Jensen, A. McKenney, D.M. Meade, D.R. Mikkelsen, I.M. Ogden. M Okabayashi, P.H. Rutherford, J.A. Schmidt, F.G.P. Seidl, S, Suckewer, F. Tenney, A.A. Mirin, M.G. McCoy, J. Killeen, M.E. Rensirik, D.E. Shumaker and C.B. Tarter, "Computational study of Impurtty Effects, Impurity Control, and Neutral Beam Injection in Large Tokanaks," Seventh Intl. Conf. on Plasma Phystcs and Controlled Nuclear Fusion Research, Innsbruck (197B), (IAEA, Vienna), I, 471.

A.A. Mirin, M.C. McCoy, J. Killeen, M.E. Rensink, D.E. Shumaker, D.L. Jassby and D.E. Post, "Fokker-Planck/Transport Analyses of Fusion Plasmas In Contemporary Beam-Driven Tokamaks," Joint Varenna-Grenoble International Symposium on Heating in Toroldal Plasmas, Grenoble (1978), 13.

R.D. Gill, K.B. Axon, G.A. Baxter, W.H.M. Clark, R.S. Hensworth, J. Hugill, J.W.M. Paul, J.B.B. Percival, R. Prentice, B.A. Powell and A.A. Mirin, "Neutra1 Injection Heating in DITE," Ninth European Conf, on Controlled Fusion and Plasma Physics, Oxford (1979), 150.

P.I. Colestock, S. Davis, P.C. Efthinion, H.P. Eubank, R.J. Coldston, L.R. Grishan, R.J. Hewryluk, J. Hovey, D. L. Jassby, D.W. Johnson, A.A. Mirin,, . Schllling, R. Scooksberry, L.D. Stewart, J.D. Strachan and H.H. Towner, "Fusion Neutron Production duting Deuterium Neutral Beam Injection inco PLT," Ninth European Conf. on Controlled Fusion and Plasma Physics, Oxford (1979), 45. 
D.V. Anderson, S.P. Auerbach, H.L. Berk, J.K. Boyd, T.A. Brengle, J.A. Byers, B.I. Cohen, W.C. Condit, J.C. Eddleman, R.P. Freis, E.H.A. Granneman, J.H. Hammer, C.W. Hartman, J. Ki lleen, B. McNamara, W.A. Newcomb. L.D. Pearlstein, M.G. McCoy, D.S. Prono, J.M. Sayer, D.D. Schnack, D.E. Shumaker, J.W. Shearer, A.C. Smith, J. Taska, W.C. Turner, D.E. Driemeyer, G.H. Miley, E.C. Morse, E. MeColl and H. Weitzner. "Theory of Field-Reversed Mirrors and Field-Reversed Plasma Cun Experiments, "Eigth Int'1. Conf, on Plasma Physics and Controlled Nuclear Fuston Research, Brussels (1980), (IAEA, Vienna), I, 469.

D.E. Baldwin, R.H. Cohen, T.A. Cutler, T.B. Kaiser, B.C. Logan, Y. Matsind.A. A.A. Mirln, L.D. Pearlsteín, M.E. Rensink and T.D. Rognlien, "Studies in Tandem Mirror Theory," Eighth Irit'l. Conf. on Plasma Physics and Controlled Nuclear Fusion Research, Brusse1s (1980), IAEA-CN-38-F4.

A.A. Mirin and D.L. Jassby, "Fokker-Planck/Transnort Studies of the Tokamair Fusion Test Reactor," IEEE Transactions on Plasma Science PS-8 (1980). 503.

J. Kflleen, A.A. Mirin, and M.G. McCoy, "A Fokker-Planck/Transport Mode? for Neutral Beam Driven Tokamaks." Modern Plasma Physics (IAEA, Vienna. 1981), 395.

J.D. Strachan, P.L. Colestock, S.L. Davis, D. Eames, P,C, Efthimion, H.P. Eubank, R.J. Goldston, L.R. Grisham, R.J. Hawryluk, J.C. Hosea, J. Hovey, D.L. Jassby, D.W. Johnson, A.A. Mirin, G. Schilling, R. Stooksberry, L.D. Stewart, and H.H. Towner, "Fusion Neutron Production during Deuterium Neutral Beam Injection into the PL: Takamak, "Nucl. Fusion 2i. $(1981), 67$.

R.W, Hazvey, M.G. MeCoy, J, Y. Hsu and A.A. Mitin, "Electron Dynamles Assoclated wh Stachastic Magnetic and Ambipolar Electric Fields," Phys. Rev. Letters 47. No. 2 (1981), 102.

D.E. Shumaker, J.K. Boyd, S.P. Auerbach and B. McNamara, "Numerica: Simulation of Transport in a Field-Reversed Mirror Plasma,"

J. Comput. Phys. 45 (1982), 266.

D.S. Harned, D.W. Hewett, C.G. Lilliequist, R.W. Moses, D.D. Schnack. J.L. Schwarzmeier, A.G. Sgro, R.L. Spencer, D.V, Anderson, J. Killeen, A.A. Mirin, N.J. O'Neill, A.I. Shestakov, D.E. Shunaker, S.P. Aluerbach, J.K. Boyd, T.A. Brengle, B.I. Cohen, J.H. Hanmer, C.W. Hartman, W.C. Turner, A.Y. Aydemir, D.C. Barnes, C. Bernard, W.M. Tang, C. Seyler and J. Tataronis, "Compact Toroidal Plasmas: Simulations and Theory." Ninth Int'1. Conf. on Plasma Physics and Controlled Nuclear Fusion Research. Baltirore (1982), (IAEA, Vienna), II, 293.

A.A. Mixin, S.P. Auerbach, R.H. Cohen. J.H. Gilmore, L.D. Pearlstein and M.E. Rensink. "Radial Transport Calculations for Tandem Mirrors." Nucl. Fusion 23 (1983). 703.

R.D. Gill, G.D. Kerbel and A.A. Mirin, "The 1-D Simulation of DITE Neutral Injection Heating Experiments," Plasma Phys. Cont. Fusion 26, 1B (1984) 341.

S.F. Auerbach. R.H. Cohen, J.M. Gilmore, A.A. MIrin and M.E. Rensink, "Plasma Transport Caused by Ion-Neutral Atom Collistons-I. Slab Model." Nucl, Fusion 24 (1984), 1951. 
T.R. Jarboe, C.W. Barnes, I. Henins, H.W. Hoida, S.O. Knox, D.A. Platts, A.R. Sherwoud, B.L. Wright, G.J. Mark1in, A.G. Sgro, R.K. Linford, A.A. Mirin and D.E. Shuraker, "Spheromak Studies on CTX," Tenth Int'1. Conf. on Plasma Physics and Concrolled Nuclear Fusion Research, London (1984), (IAEA, Vienna), I1, 501.

R.E. Siemon, W,T. Armstrong, R.E. Chrien, P, L, Klingner, R.K. Linford, K.F. McKenna, D.I. Rej, J.L. Schwarzmeier, A.G. Sgro, E.G. Sherwood, R.L. Spence, M. Tuszewski, N.T. Gladd, D.S. Harned, D.E. Shumaker and C.E. Seyler, "Theoretical Studies of Field-Reversed Configurations (FRCs) and Experimentel Study of the FRC During Translation," Tenth Intl. Conf. on Plasma Physics and Controlled Nuclear Fusion Research, London (1984), (IAEA, Vienna), II, 511.

J. Killeen, G.D. Kerbel, M.G. McCoy and A.A. Mirin, Computational Methods for Kinetic Models of Magnetically Confined Plasmas, Sprínger-Verlag, 1986.

D.C. Barnes, W.T. Armstrong, E.J. Caramana, R.E. Chrien, W.N. Hugrass, H.R. Lewis, R.K. Linford, K.M. Ling, K.F. McKenna, D.J. Rej, J.L. Schwarzmeier, R.E. Siemon, M.M. Tuszewski, K.A. Herley, D.S. Harned, S. Okada, C.E. Seyler, D.E. Shumaker, H. Tuczek, G.C. Vlases, R.D. Brooks, Z.A. Pietrzyk, K.D. Bahn, D. Lotz, R. Ramen, and J. Wight, "Theoretical and Experimental Studies of Field-Reversed Configurstion, "Eleventh Intl. Conf. on Plasma Physics and Controlled Nuclear Fusion Research, Kyoto, Japan (1986). IAEA, Vienna, II, 673.

D.E. Shumaker, "Transport Simulatior, of a Field-Reversed Configuration Plasma," Fusion Tech. 13 (1988), 555.

\section{R.eports, Extended Abstracts and Invited Seminars}

K.D. Marx, B. Kelly, J. Killeen, A.A. Mirin and M.E. Rensink, "A Two-Dimensional Transport Code for Toroldal Plasmas," Seventh Conf. on the Numerical Simulation of Plasmas, New York (1975), 19.

A.A. Mirin, J. Kflleen, K.D. Marx and M.E. Rensink, "A Radial Transport/Fokker-Planck Model for a Tokamak Plasma," Seventh Conf. on the Numerical Simulation of Plasmas, New York (1975), 15.

D.E. Shumaker, "Calculation of Transport Coefficients in an Axisymetric Torus." UCRL-52218 (1977).

A.A. Mirin, M.G. MeCoy, J. Kílleen and D.E. Shumaker, "FPTE - A Super-Hybrid Fokker-Planck/Transport/Equilibrium/Monte Carlo Neutrals Code for Non-Circular Tokamaks," Eighth Conf. on the Numerical Simuia: :on of Plasmas, Monterey (1978), PD-1.

A.A. Mirin, D.L. Jassby, and M.G. McCoy, "Should Operation of the TFTR as a CII be Considered," presented to Ad Hoc Commitcee on TFTR Review, Germantawn (Oct. 1978).

P.l. Colestock, 5. Davis, P.C. Efthimion, H.P. Eubank, R.J. Goldston, L.K. Grishom, R.J. Hawryluk, J. Hovey. D.L. Jassby, D.W. Johnson, A.A. Mirin, G, Schilling, R. Stooksberry, L.D. Stewart, J.D. Strachan and H.H. Towner, "Fusion Neutron Production during Deuterium Neutral Beam Injection into PLT," Princeton Plasma Physles Labotatory Report PPPL-TM-32, (1979). 
S.P. Auerbach, H.L. Berk, J.K. Boyd, B. McNamara and D.E. Shumaker, "Two Dimensional Time-Dependent Transport in Field Reversed Equilibria," US-Japan Joint Symposium on Compact Toruses and Energettc Particle Injection, Princeton (1979), UCRL-B3714.

A.A. Mirin and D.L. Jassby, "Modeling of Reacting Tokamak Plasmas wi il, n Fokker-Planck/Transport Code," 1979 IEEE Int'1. Conf. on Plasma Science. Kontreal (1979), 5B8.

D.L. Jassby, P.L. Colestock, S. Davis, P.C. Efthimion, H.P. Eubank, R.J. Goldston, L.R. Grisham, R.J. Hawryluk, J. Hovey, D.W. Johnson, A.A. MIIn, G. Schilling, R. Stooksberry, L.D. Stewarc, J.D. Strachan and H.H. Towner, "Fusion Neutron Production during Deuteríum Neutral Beam Injection into Deuterfum Plasmas in the PLT Tokamak," 1979 IEEE. Int'1. Conf. on Plasma Science, Montreal (1979), 289.

A.A. Mirin and D.L. Jassby, "Fokker-Planck/Transport Simulations of Beam-Injected Plasmas in the Princeton Large Torus," UCRL-85119 (1980).

D.E. Shumaker, J,K. Boyd, S.P. Auerbach and B. McNamara, "Reversed Ficld Mirror Transport Code." Third Symp. on the Physics and Technology of Compact Toroids, Los Alamos (1980), UCRL-85133.

D.E. Shumaker, J,K, Boyd, S.P. Auerbach, H, L, Berk and B. McNamara, "Field-Reversed Mirror Transport Code." Annual Controlled Fusion Theory Conf., Tucson (19B0), 2C17; and Ninth Conf. on the Numerical Simulation of Plasmas, Evanston (1980), PB-10.

A.A. Mirin, J. Killeen and M.E. Rensink, "A Transport Code for Tandem Mirror Devices," Ninth Conf. on the Numerical Simulation of Plasmas. Evanston (1980), PA-B.

M.G. McCoy and R.W. Harvey, "Effects of Anomalous Transport on Lower Hybrid Electron Heating." Proc. Fourth Topical Cont. on Radio Frequency Piasma Heating, Aust in (1981), VCRL-85255.

D.E. Shumaker, J.K. Boyd, B. McNamara and W.C. Turner, "Numeri:al Simulation of Beam Heated Compact Torus," Fourth Symp. on the Physics and Technology of Compact Toroids, Livermore (1981), UCRL-86322.

D.E. Shumaker, J.K. Boyd, B. McNamara and W.C. Turner, "Numerical Simulation of the Beta II Experiment." UCRL-85579 (1981).

J.M. Gilmore, S.P. Auerbach, R.H. Cohen, A.A. Mirin, L.D. Pearlstein and M.E. Rensink, "Quenching of Radial Transport in Tandem Mirtors," Mirror Theory Month1y, Lawrence Livermore National Laboratory, June 1982.

D.E. Shumaker, "Equilibrium Calculation of Compact Torolds Using a Flux Surface Coordinate System," Tenth Conf. on the Numerical simulation of Plasmas, San Dlego (1983), $2 B 14$.

D.E. Shumaker, "Numerical Simulation of Transport in a Field Reversed Configuration," US-Japar Symposium on Compact Foroid Research. Priflectory (1984).

A.A. Hirin, "Running FPT for a D-T Neucral Injection Problem," UCID-30201 (1984). 
D.E. Shumaker, "Transport Simulation of a Field-Reversed Configuration Plasma," Proc. Seventh CT Symposium. Santa Fe (1985).

D.E. Shumaker, "Transport In Field-Reversed Configuration; Comparison of Sinulation and Experiment," LLNL Report UCRL-94433, (1987).

\section{Conference Abstracts}

R.P. Frels, M.E. Rensink, J, Killeen and A.A. Mirin, "Mulflu, a 1-D Multifluid Code," Bull. An. Phys. Soc. 19, 922 (1974); Albuquerque.

A.A. Mirin, J. Killeen, K.D. Marx, and M.E. Rensink, "Computat Loral Study of the Toroidal Fusion Test Reactor," Bull. Am. Phys. Soc. 26., 1257 (1975); St. Petersburg.

M.G. McCay, A.A. Mirin, M.E. Rensink, D.L. Jassby, J. Killeen and K.D. Marx, "Computational Study of the Counterstreaming Ion Torus," Bul1. Am. Phys. Soc. 21, 1064 (1976); San Francisco.

A.A. Mirin, M.G. McCoy, D.L. Jassby and J. KIlleen, Fokker-Planck/ Transport Simulations of Counterstreaming Ion Plasmas in the PDX Experiment," Annual Controlled Fusion Theory Conf., San Diego (1977), B15.

M.G. McCoy, J. Killeen, A.A. Mirin, M.E. Rensink and D.E. Shumaker "Fokker-Planck/Transport Mocel of Non-Circular Axisymmetric Devices," BulI. Am. Phys, Soc. 22, 1116 (1977); Atlanta.

A.A. Mirin and D.L. Jassby, "Fokker-Planck/Transport Studfes of the PDX using a Self.Consistent Neutrals Package," Bull. All. Phys. Soc. 22, 1116, (1977); Atlanta.

A.A. Mirin and D.L. Jassby, "Fokker-Planck/Transport Studies of the PDX, PL.T and TFTR Incorporating a Self Consistent Neutrels Treatment, Annual Controlled Fision Theory Conf., Gatlinburg (1978), C10.

A.A. Mirin, M.G. McCoy and D.L. Jassby, "Fokker-Planck/Transport Studies of the TFTR," Bull. Am. Phys. Soc. 23, B65 (1978); Colorado Springs.

D.L. Jassby, P.L. Colestock, R... Goldston, H. P. Eubank, J. Hovey, J.S. Strachan, H.H. Towner and A.A. Mirin, "Fusion-Neutron Production in PLT Plasmas Heated by Deuterium Beams," Bul1. Am. Phys. Soc. 23, 796 (1978); Colorado Springs. (A.A. Mirin added to author 11st subsequent to publication in Bulletin)

A.A. Mirin, R.H. Cohen, M.E. Rensink and J. Killeen, "Preliminary Results of a Tandem Mirror Transport Code," Annual Controlled Fusion Theory Conf. Hount Pocono (1979), 2B26.

D.E. Shumaker, M.G. McCoy, J. Killeen and A.A. Mirin, "Two Transport Models for Nonclrcular Axisymmetric Devices," Annual Controlled Fusion Theory Conf., Mount Pocono (1979), 2C21.

D.E. Shumaker, B. McNamara and J.K. Boyd, "Field Reversed Mirror Transport Code," Bull. An. Phys. Soc, 24, 955 (1979); Boston.

M.E. Rensink, B.A. Witin, K.H. Cohen and J. Killeen, "A Radial Transport Hodel for TWX," Bul1. As. Phys. Soc, 24, 1059 (1979); Boston. 
A.A. Mirin and D.L. Jassby, "Nonlinear Transport Simulations of Neutral Beam-Heated Plasmas in PLT and PDX," Bull. Am. Phys. Soc, 24, 94 (1). (1979); Boston.

M.E. Rensink and A.A. Mirin, "Some Factors Influencing the Structure of Tandem Mirxor Plasma," Annual Controlled Fusion Theory Conf., Tucson (1980), 1B18

M.G. McCoy, A.A. Mirin and R.W. Harvey, Mumerical Modeling of Electron Diffusion due to Disturbed Flux Surfares," Annual C::trolled Fusion Theory Conf., Tucson (1980), 2B5.

A.A. Mirin and M.E. Rensink, "Radial Transport in Tandem Mirrors." Bull. All. Phys, Soc. 25, 880 (2980); San Diego.

D.E. Shumaker, J.K. Boyd, S.P. Auerbach and B. MeNamara, "Transport in Field-Reversed Mirror," Bull. Am. Phys. Soc. 25, 979 (1980); San Diego.

M.G. McCoy, A.A. Mirin, R.W. Harvey and J.Y.-Hsu, "Numerical Studies of Electron Diffusion due to Disturbed Flux Surfaces in Tokamaks,"

Bul1. Am. Phys. Soc. 25, 847 (1980); San Diego.

M.G. McCoy and R.W. Harvey, "Anomalous Transport Effects on Electron Heating by a Finite Spectrum of Lower Hybrid Waves," Annual Controlled Fusion Theory Conf., Austin (1981), 1C32.

R.W. Harvey, J.-Y. Hsu and M.G. McCoy, "The Amblpolar Electric Field in Stochastic B-Field Models," Annual Controlled Fusion Theory Conf., Austin (1981), 3A3.

D.E. Shumaker, J.K. Boyd, S.P. Auerbach and B. McNamare, "Numerica1 Simulation of the Beta II Experiment," Annual Controlled Fusion Theory Conf., Austin (1981), 3B39,

J.M. GIlmore, A.A. Mirin, M.E. Rensink and S.P. Auerbach, "Radial Transport Computations for Tandem Mirrors." Bull. Am. Phys. Soc. 26, 1005 (1981); New York.

R.D. Gill, G.D. Kerbel and A.A, Mirin, "Nonlinear Transport Simulations of Neutral Beam-Heated Plasmas in DITE," Bull. Am. Phys, Soc. 26, 1065 (1981); New York.

D.E. Shumaker, J.K. Boyd, B. McNamara and W.C. Turner, "Numerica1 Simulation of a Beam Heated Compact Torus," Bull. Am. Phys. Soc, 26, 881 (1981); New York.

S.P. Auerbach, R.H. Cohen, J.M. Gilmore, A.A. Mirin, L.D. Pearlstein and M.E. Rensink, "Calculation of Self-Consistent Radial Electric Fields in Tandem Mirrors," Annual Ccntrolled Fusion Theory Conf., Santa Fe (1982), $1 \mathrm{C32}$.

J.M. Gllmore, S.P. Auerbach, R.kl. Cohen, R.A. Jong, A.A. Mirin, and H.E. Rensi:?, "Tanden Mirror Radial Transport Calculations,"

Bul1. Am. Phys. Soc. 27, 1116 (Igg\%); New Orluans. 
S.P. Auerbach and D.E. Shumaker, "Ion Thermal Conduction in Compact Toroids: Comparison of Theory. Simulations and Experiments."

Bull. Am. Phys. Soc. 27, 1113 (1982): New Orleans.

J.K. Gilmore, S.P. Auerbach, R.H. Cohen, A.A. Mirin, L.D. Pearlstein and M.E. Rensink, "Self-Consistent Calculation of Radial Transport in Tandetn Mirrors," Annual Controlled Fusion Theory Conf.. Arlington (1983), 2 E3.

D.E. Shumaker, "Numerical Calculation of Axisymetric Compact Torus Equilibrium using Finite Elements," Annual Controlled Fusion Theory Conf., Arlington (1983), 3P23.

J.M. Gilwore, S.P. Auerbach, D.E. Baldwin, R.H. Cohen and A.A. Mirin, "Self-Consistent Study of End-Hall Potential Control in Tandem Mirrors," Bull. Am. Phys. Sor. 28, [036 (1983); Los Angeles.

D.E. Shumaker, "Transport Calculation for a Field Reversed Configuration" Annual Controlled Fusion Theory Conf., Lake Tahoe (1984), 397.

D.E. Shumaker, "Trarsport in a Field Reversed Configuration: Comparison of Simulation and Experiment," Bu11. Am. Phys. Soc. 29 (Boston, 1984) 1327.

D. E. Shumaker, "Numerical Simulation of Transport in a Fleld Reversed Configuration; Comparison with Experiment," Annual Controlled Fusion Theory Meeting, Madison (1985), 1 Q16.

D.E. Shumaker, "Numerical Simulation of Equilibriun and Transport in a Field-Reversed Configuration," Bull. Am. Phys. Soc. 30 (San Diega, 1985), 1409 (Invited Faper).

D.E. Shumaker, "Numerical Simulation of Transport in Field Reversed Configuration," Annual Controlled Fusion Theory Meeting, New York (1986), 2 CIO. 
Appendix C - Fokker-Planck References

\section{Papers and Inviced Talks}

M.E. Rensink, T.K. Fowler, R.P. Freis, J. Killeen, A.A. Mirin, R.W. Moir, L.D. Pearlstein, R.F. Post, C.G. Tull, L.S. hall, B. McNamara, J.K. Boyd, C.H. Flnan, III, D. Fuss, and C.A. Wilgus, "Theoretical Studies of Plasmis Confinement in Magnetic Mirrors," Fifth Int1. Conf. on Plasma Physics arr Controlled Nuclear Fusion Research, Tokya (1974), (IAEA, Vienna), 311.

H.L. Berk, H,P. Furth, D.L. Jassby, R.M. Kulsrud, C.S Lui, M.N. Rosenbluth, P.H. Rutherford, F.H. Tenney, T. Johnson, J. Killeen, A.A. Mirin and M.E. Rensink, "Two Energy Component Toroidal Fusion Devices," Fifth Intl. Conf. on Plasma Physies and Controlled Nuclear Fusir: Research, Tokyo (1974), (IAEA, Vienna). 569.

J.A. Byers, R.P. Freis, J. Killeen, E. Lee, B. MeNamara, A.A. Mirin, and M.E. Rensink, "Computational Studies of Two Component Mirror Reactors," Fifth Intl. Conf. on Plasma Physies and Controlled Nuclear Fusion Resparch. Tokyo (1974), (IAEA, Vienna), 551.

K.D. Marx, A.A. Mirin, M.C. McCoy, M.E. Rensink and J. Killeen, "Calculation of $\left(\bar{\sigma} \dot{v}_{\mathrm{DT}}\right)$ for Anisotropic Mirror and Toroidal Distributions." Nucl. Fusion 16. No. 4 (1976), 702.

D. L. Jassby, R.M. Kulsrud, F.W. Perkins, J. R1lleen, K.D. Marx, M.G. McCoy. A.A. Mirin, M.E. Rensink and C,G. Tul1, "Counterstreaming-Ion Tokamak Fusion Reactors," Sixth Intl, Conf. on Plasma Physles and Conerolled Nuclear Fusion Research, Berchtesgaden, FRG (1976), (IAEA, Vienna) II, 435

J. Killeen, A.A. Mirin and M.E. Rensink, "The Solution of the Kinftic Equations for a Multispecies Plasma," in Methods in Computational Ihysics 16. (Academfic Press, New York, 1976), 389.

J.G. Cordey, K.D. Marx, M.G. McCoy, A.A. Mirin, M.E. Rensink, "A Legendre Expansion Method for Computing (av) for Reactant Distribution Functlons," J. Compur. Phys. 28 (1977), I15.

J. Killeen and A.A. Mirin, "Numerical Solution of the Fokker-Planck Equations for a Multispecies Plasma," College in Theoretical and Computational Plasma Phys., Trieste (1977). (IAEA, Vienna).

A.A. Mirln, J. Killeen and C.J.H. Watson. "Some Preliminary Q Calculations for Toroldally Linked Mirror Reactors," Nucl. Fusion 17 No. 1 (1977), 47.

R.H, Cohen, M.E. Rensink, T.A. Cutler and A.A. Mirin, "Coilistonal Loss of Electrostatically Confined Species in a Magnetic Mirror," Nucl. Fusion 18 (1978), 1229. 
B.C. Logan, W. L. Barr, D.J. Bender, G.A. Carlson, W.L. Dexter,

J.N. Dogeett, R.S, Devoto, J,F. Fink, T.K. Fowler, G.W. Hamilton, D. Lappa,

J.D. Lee, W.D. Neef, Jr., A.A.Mirin, R.W. Moir, M.A. Peterson and

M.E. Rensink, "Tandem Mirror Reactors," Seventh Jnt l. Conf. on Plasma

Physics and Controljed Nuclear Fusion Rescarch, Innshruck (19/8), (IAEA,

Vienna). III, 401 .

B.G. Logan, A.A. Mirin, H.E. Rensink and T.K. Fowler, "Calculacion of the Fusion Powet Gain for a DD Tandem Mirror Reactor," Fizika Plasma 4 (1978), 542.

B.G. Logan, A.A. Mirin and M.E. Rensink, "An Analytic Model for Classical Ion Confinement in Tandem Mirror Plugs," Nucl. Fus. 20 (1980), 1613.

R.W. Harrey, K.D. Marx, and M.G. McCoy. "Nonlinear Fokker-Planck Studies of RF Current Drive Efficiency," Nuci. Fusion 21 (1981), 153.

M.G. MeCoy, A.A. Mirin and J. Killeen, "FPPAC--A Two-Dimensional Multispecies Nonlinear Fokker-Planck Package," Gomput. Phys . Commun, 24. No. $1(1981), 37$.

A.A. Mirin and G.P. Tomaschke, "Is Fusion Reactivity in TFTR affected by Distortions of the Bulk Ions from Maxweliians?, Nucl. Fusion 23 (1982). 1379 .

M.E. Rensink, R.H. Cohen, A.A. Mirin and G.P. Tomaschke, "Electrostatically Trapped Electrons in Thermal Barrier Tandem Mirrors," Nuc1. Fusion 24 $(1984), 49$.

F.W. Perkins, E.J. Valeo, D.C. Eder, D.Q. Hwang, A. Kritz, C.K. Phillips, I.C. Sun, D.G. Swanson, G.D. Ketbel, M.C. McCoy, J. Killeen, R.W. Harvey, S.C. Chiu, K. Hzantdis, V. Krapchev, D. Hewett and A. Bors, "Theoretical Studies of LH Current Drive and Ion Cyclotron Heating in Tokamaks," Tenth Intl. Conf. on Plasma Physics and Controlled Nuclear Fusion Research, London (1984), (IAEA, Vienna), II, 513.

G.D. Kerbel and M.G. McCoy, "Kinetic Theory and Simulation of Multispec:es Plasmas in Tokamaks Excited with Electromagnetic Waves fn the Ion Cyclotron Range of Frequencies," Phys. Fluids 28 (1985), 3629.

G.D. Kerbel and M.G. McCoy, "Kinetic Theory and Simulation of Multi-Species Plasmas in Tokamaks Excited with ICRF yicrowaves." Annual Controlled Fusion Theory Meeting. Madison (1985), 3B2 (Oral Presentation).

G.D. Kerbel and M.G. McCoy, "Collision Broadened Resonance Localization In Tukamaks Excited with ECRF Waves," 3rd European Workshop on Problems in the sunerical Modeling of Plasmas, Varenna (1985), Comput. Phys. Commun. 40 $(1986), 115$

M.G. HcCoy. G.D. Kerbel and R.W. Harvey, "Three-Dimensional Simulations of Electron Cyclotron Heating," 3rd European Workshop on Problems in the Liumerical Modeling of Plasmas. Varenna (1985). Comput. Phys. Commun. 40 (1986), 105 .

J. Killeen, G.D. Kerbel, M.G. McCoy and A.A. Mirin. Gomputational Methods for Kinet lc Models of-Magnetically Confined Plasmas, Springer-Verlag, 1986 , 
J. Schmidt, G. Bateman, D. Blackfield, L. Bromberg, C. Bushnell,

J. Cirrolo, D. Cohn, P. Colestock, C. Flanagan, M. Greenwald, W. Houlber?,

M. Hughes, D. Ignat, R. Izzo, S. Jardin, G. Kerbel, L.P. Ku,

G. Kuo-Petravic, B. Ifpschultz, B. Montgomery, R. Parker, C. Paulson,

Y-K.M. Peng, M. Petravic, C.K. Phillips, M. Phillips, N. Pomphrey, D. Post .

F. Puhn, T. Shannon, J. Sheffield, D. Stgmar, D. Strickler, D. Swain.

G. Swanson, R. Thome, A. Todd, N. Uckan, R. White, S. Wolfe, and $K$. Young.

"A Compact Ignition Experiment." Eleventh Int'1. Conf. on Plasma Physics and Controlled Nuclear Fusion Research, Kyoto, Japan (1986), (IAEA,

Vienna), III, 259.

H.W. Hendel, A.C. England, D.L. Jassby, A.A. Mirin and E. B. Nieschmidt, "Fusion-Neutron Production in the TFTR with Deuterium Neutral-Beam Injection," J. Fusion Energy $\underline{5}$ (1986), 231.

A.A. Mirin, G.W. Shuy and D. Dobrotr, "Plasma Performance of the Central Cell of Cat-D Tandem Mirror Reactor," IEEE Trans. Plasma Sci. PS-15 (1987). 42 .

R.S. Devoto, L.L. LoDestro and A.A. Mirin, "Trapping Races in Tanden Mirror Thermal Barriers," Nucl. Fusion 27 (1987), 255.

J. Killeen, G.D. Kerbel, M.G. MeCay, A.A. Mirin, E.J. Horowitz and D.E. Shumaker, "Computer Models for Kinetic Equations of Magnetically Confined Plasmas," 1987 Int'l. Conf. on Plasma Physies, Klev.

M.R. Franz, G.D. Kerbel and M.G. McCoy, "The Numerlcal Solution of the Relativistic Bounce-Averaged Fokker-Planck Equation for a Kagnetically Confined Plasma," submiteed to J. Comput. Phys.

B.I. Cohen, R.H. Cohen, G.D. Kerbel, B.G. Logan, Y. Matsuda, M.C. MeCoy, W.M. Nevins, T.D. Rognlien, G.R. Smith, R.W. harvey, A.H. Kritz, P.T. Bonol1 as $M$. Porkokab, "Microwave Heating and Current Drive in Tokamaks," Twelfth Int'1. Conf. on Plasma Physics and Controlled Nuclear Fusion Research, Nice (1988), IAEA-CN-50/E-IV-10.

A.A. Mirin and M.C. MeCoy, "SIGU5D, a Routine to Compute the Ruaction Rates of Interacting Distribution Functions," to appear in Comput. Phys.

Commun.

A.A. Mirin, K.G. McCoy, G.P. Tomaschke and J. Killeen, "FFPACB8: A Two-D1mensional Multispecies Nonlinear Fokker-Planck Package," to appear in Comput. Phys. Commun.

R.w. Harvey, M.G. McCoy and G.D. Kerbel, "Power Dependence of Electron Cyclotron Current Drive for Low and High Field Absorption in Tokamaks." to appear in Phys. Rev. Lett.

Reports, Extended Abstracts and Invited Seminars

A.A. Mirin, "Isotions, A One-Dimensional Multispecies Fokker-Planck Compucer Code," UCRL-5]616 (1974).

A.A. Mrin, "Hyturid I, a Two-Dimensional Fokker-Planck Code," UCRL-51598 (1974). 
A.A. Mirin, "Hybrid II, A Two-Dimensional Multispecies Fokker-Planck Compurer Code," UCRL-51615, Rev, I (1975).

J. Killeen, K.D. Marx, A.A. Mirin, and M.E. Rersink, "Energy Multiplicarian and Transport in a Two-Component Torus," Seventh European Conf. on Controlled Fusion and Plasma Physics, Lausanne (1975), 22.

K.D. Marx, M.G. McCoy, A.A. Mirin, M.E. Rensink and J. Killeen, "A Legendre Expansion Method for Computing (ov) for Reactant Distribution Functions," UCRL- $78362\langle 1976\}$.

R.L. Berger, "Fokker-Planck Calculations of Runaway Particle Effects in Plasmas," Ph. D. Thesis. University of California at Davis (1978).

M.G. McCoy, A.A. Mirin and J. Killeen, "A Vectorized Fokker-Planck Package for the CRAY-1," Scientific Computer Exchange Meeting, Livermore (1979). UCRL-83206.

M.G. McCoy, A.A. Mirin, A.I. Shestakov and J. Killeen, "Two CRAY-Optimized Computer Packages: A Nonlinear Fokker-Planck Equation Solver and an Axisymmetric Banded Linear Systems Solver, "Ninth Conf. on the Numerical Simulation of Plesmas, Evanston (1980). PC-8.

G.D. Kerbel and M.G. McCoy, "Bounce Averaged ICRH for Toroidal Devices: Application," Fifth Topical Conf. on RF Heating, Madison (1983), A.I.2.

G.D. Kerbel and M.G. McCoy, "Bounce-Averaged Collisional and Resonant Diffusion Calculations for Toroidal Devices.: Tenth Conf, on the Numerical Simulation of Plasmas, San Diego (1983), 2 C13.

G.D, Kerbel and M.G. McCoy, "Computational Fokker-Planck Models of Mulct-Species Plasmas in Non-Uniform Magneric Fields: Supra-Thermal Effects of Auxilfary Heating in Large Tokamaks," IAEA Technical Comn. Meeting on Operating Plans for Large Tokamak Experiments, Princeton (1984).

C.D. Kerbel and M.G. McCoy, "ICRF Excitation of Plasmas in Non-Uniform Magnecic Fields: A Fokker-Planck Approach," US-Japan Workshop on RF Heating of Plasmas. La Jolla (1984).

A.A. Mirin, "How to Run Hybrid-II for Mirror Scenarios," UC1D-30202 (1984).

A.A. Mirin, "How to Run TDMFP," UCID- 30208 (1984).

R.W. Harvey. M.C. MeCoy and G.D. Kerhel. "Three Dimensional Stmularions of ECH. "Eleventh Int'1. Conf. on the fiumerical Simulation of Plasmas. Xontreal (1985), 1817.

C.W. Shuy, S. Tamor, P.D. Stroud. A.A. Mirin and D. Dobrott, "Assessment of Proton Based fusion fuel cycles." Science Applications Int'l. Corp. Report SA]C-85/3005 (1586).

R.S. Devoto, A.A. Mirin, K. Tani, S. Yamanoto, M. Sugihara and M. Azumi. "tivutral Beam Driven Current with Bootstrap Effects," Japan Nuclear Fusion Aceling. Japan (1987).

P.H. Harvey, M.G. McCoy and C.D. Kerbel, "3-D Bounce-Averaged Fokker-Planck: rilculation af Ëlectron Cyclotron Current brive Effictency," Seventh 
Topical Conf. on Applications of Radio-Frequency Power to Plasmas, MIP Conf. Proceedings $159(1987), 49$.

M.G. McCoy, G.D. Kerbel and R.W. Harvey, "Three-Dimensional Model of Electron Cyclotron Heating, Seventh Toplcal Conf, on Applications of Radio-Frequency Power to Plasmas, AIP Conf. Proceedings 159 (1987), 77.

G.D. Kerbel, "Coherence Limited Resonant Diffusion," Seventh Topleal Conf. on Applications of Radio-Frequency Power to Plasmas, AIP

Conf. Proceedings 159 (1987), 430 .

G.D. Kerbel, M.G. McCoy and R.W. Harvey, "Coherence Limlted Resonant Diffusion," Twelfth Conf. on the Numerical Simulation of Plasmas, San Franctsco (1987), PML1.

R.S. Devoto, M.E. Fenstermacher, B.G. Logan and A.A. Mirin. "Tiber II Baseline Operation, "Twelf th IEEE Symposium an Fusion Engineering. Monter(v (1987).

G.R. SmIth, R.H. Cohen, G.D. Kerbel, M.G. McCoy, R.W. Harvey and A.H. Kritz, "Electron-Cyclotron Current Drive Efficiency with Steady State Sources in the ITER Tokamak," ITER Specialists" MeetIng on Current Erive and Heating. Garching (1988).

\section{Conference Abstracts}

J. Killeen, A.A. Mirin and M.E. Rensink, "Energy Multiplication Studies of the Two Component Torus with Major Radius Compression,"

Bull. Am. Phys. Soc. 19, (1974); Albuquerque.

A.A. Mirln, J. Killeen and M,E. Rensink, "Multi-Specfes Fokker-Planck Calculations for the Two Component Torus," Bul1. Am. Phys, Soc, 19, 974 (1974); Albuquerque.

M.E. Rensink, J. Killeen and A.A. Mirin, "Computational Studies of Mirror Confinement," Bull. Am. Phys. Soc. 19,920 (1974); Albuquerque.

T.A. Curler, J.A. Byers, D. Freeman, B. McNamara, A.A. Mirin and M.E. Rensink, "Buildup of Two Component Mirror Plasmas," Bul1. Am. Phys. Soc. 19,921 (1974); Albuquerque.

A.A. Mirin, J. Killeen, K,D. Marx and M.E. Rensink, "Energy Multiplication Studies for a Pulsed Two Component Torus," Annual Meeting on Theoretical Aspects of Controlled Thermonuclear Research, Rosslyn (1975), 68.

K.D. Marx, J. Killeen, A.A. Mirin and M.E. Rensink, "Energy Multiplication Studies for a Steady Stace Two Component Torus," Annual Meeting on Theoretical Aspects of Controlled Thermonuclear Research, Rosslyn (1975), 64.

M.E. Rensink, A.A. Mirin and J. Killeen. "Computational studies on Mirror Confined Plasmas," Annual Meeting on Theoretical Aspects of Controlled Thermonuclear Research, Rosslyn (1975), 80.

A.A. Mirin, M.E. Kensink and D.L. Jassby, "Fokker-Planck Studies of the Counterstreaming Ion Torus." Annual Meting, on Theoretical Asperets of Controlled Thermonucjear Resfarch. Madisat: (19/6), 2A-15. 
A.A. Mirin, M.E. Rensiuk and D.1. Massby, "Fokker-l'lanck Stadies of ilso" C.I.T." Bull. Am. Phys. Sac. 21, 1064 (19/6); San Fratacisco.

K.D. Marx, W.L. Barr, R.W. Moir and C.E. McDowe11, "A Monte Carlo Calculation of Collisional Effects in a Mirror-Confined Plasma," Annual Meeting on Theoretical Aspects of Controlled Thermonuclear Research, Madison (1976), 1C-11.

M.G. McCoy, J. Killeen, K.D. Marx, A.A. Mirin and M.E. Rensink, "Calculations of ( $\left.\bar{\sigma} \bar{v}_{\mathrm{DT}}\right)$ for Anisotroplc Mirror and Toroidal Distributions," Anmual Meeting on Theoretical Aspects of Controlled Thermonuclear Research. Madison (1976), 2B-11.

A.H. Futch, R.P. Freis and A.A. Mirin, "Plasma Bulld-up Calculations of Neutral Beam Injection with a Radially Dependent Fokker-Planck Code," Bul1. Am. Phys Soc. 21, 1182 (1976); San Francisco.

T.A. Cutler, A.A. Mirin, L.D. Pearlstein and M.E. Rensink, "Bounce Average Code Mirror Plasma Studies," Bul1. Am. Phys. Soc. 2), 1187 (1976); San Francisco.

K.D. Marx, T.J. Dolan, R.W. Moir and G.E. McDowell, "Trapping Rates and Loss Rates for Electrons in an Electrostatically Plugged Cusp,"

Bul1. Am. Phys. Soc. 21, 1044 (1976); San Francisco.

B.G. Logan, T.K. Fowler, A.H. Futch, A.A. Mirin and M.E. Rensink, "The Tandem Mizror Concept," 18th Annual Meeting of the DIvision of Plarma Physics of the Am. Phys. Soc., San Francisco (1976) (post-deadline paper).

M.E, Rensink, R.H, Cohen, T.A. Cutler and A.A. Mirin, "Particle Confinement. by Ambipolar Pocentials in Mirror Machines," Annual Controlled Fuston Theory Conf., San Diego (1977), B16.

R.H. Cohen, M.E. Rensink and A.A. Mirin, "Tandem .irror Confinement Studies," Annual Controlled Fusion Theory Conf., San Diego (1977), I4.

T.A. Cicler, R.H. Cohen, M.E. Rensink and A.A. Mirin, "Ambipolar Potential-Aided Mirror Confinement," Bul1. Am. Phys. Soc. 22, 1066 (1977); Aclanta.

K.D. Marx and R.L. Berger, "Numerizal Computation of Runaway Particle Effects," Bull. Am. Phys. Soc. 22, 1137 (1977); Atlanta.

K.D. Marx, R.W. Harvey and J.M. Rawls, "Fokker-Planck Studies of Plasma Heating and Current Generation due to RF Induced Quasilinear Diffusion, * Annual Contralled Fusion Theory Conf., Gatlinburg (1978), $c 9$.

K.D. Marx, R.W. Harvey and J,M. Rawls. "Numerical studies of Current Generation by RF-Induced Quasilinear Diffusion of Electrons," Bull. Ain. Phys. Suc. 23, 765 (1978); Colorado Springs

Y D. Marx, R.W. Harvey, V.S. Chan and J.M. Rawls, "Lower Hybrid Election Serfidau Damping and Current Drjye in the Presence of an Applied DC Electric fikld and Transport lossis," Annual Contrulled Fusion Theory Conf. Mount lercono $(1979) .185$. 
R.W. Harvey, J.C. Riordan J.L. Luxon and K.D. Marx, "Studies of Current Due to RF-Induced Runaway in the DIIA Lower Hybrid Experiment." Annual Controlled Fusion Theory Conf., Mount Pocono (1979), IC43.

R.H. Cohen, M.E. Rensink, A.A. Mirin and J.A. Dorning, "Plug Fluxes in Thermal Barrier Tandem Mirrors," Bull. Am. Phys. Soc. 24, 1060 (1979); Boston.

A.A. Mirin, I.B. Bernstein, R.H. Cohen and M.E. Rensink, "Fokker-Planck Studies of the Interaction between Trapped and Untrapped Electrons in Magnetic Mirrors," Annual Controlled Fusion Theory Conf., Tucson (1980). $2 A 2$.

A.A. Mirin, G.P. Tomaschke, B.G. Logan and M.E. Rensink, "Fusion Efficiency of a D-D Tandem Mirror Reactor," Annual Controlled Fusion Theory Conf.. Austin (1981), 2c30.

M.E. Rensink, A.A. Mirfn and G.P. Tomaschke, "Classical Confinement of Strongly Heated Ions and Electrons in Tandem M1rrors," Bull. Am. Phys. Soc. 26. 1007 (1981); New York.

G.D. Kerbe1, M.G. McCoy, A.A. MIrin and R.W. Harvey, "FPPAC-2, A Vectorized Bounce-Averaged Non-LInear Fokker-Planck Package," Bull. Am. Phys. Soc. 26, 1065 (1981): New York.

A.A. Mirln and G.P. Tomaschke, "Do Distortions of the Bulk Ions from Maxwellians Affect Fusion Reactivity in TFTR?, "Annual Concrolied Fusion Theory Conf., Santa Fe (1982), 1C31.

G.D. Kerbel and M.G. HcCoy, "Bounce-Averaged Fokker-Planck/Quasil Inear Diffusion Calculations in Toroidal Devices," Annual Concrolled Fusion Theory Conf., Santa Fe (1982), 2DF.

G.D. Kerbel and M.G. McCoy, "ICRH Ion Runaway ReactIvicy Enhancement," Bul1. Am. Phys. Soc. 27, 1078 (1982); New Orleans.

M.G. McCoy, C.D. Kerbel, S.C. Chiu and R.W. Harvey, "Bounce-Averaged Calculations of ICRF Induced Ion Slideway/Fusion Reactivity Enhancement." Annual Controlled Fusion Theory Conf., Arlington (1983), 2R22.

G.D. Kerbel and M.G. McCoy, "Bounce-Averaged ICRH for Toroldal Devices," Annual Controlled Fusion Theory Conf., Arlington (1983), 3 P22.

E. Horowlez, A.A. Mirin, G.W. Shuy and D. Dobrott, "Fokker-Planck Studies of a D-D Tanden Mirror keactor," Bul1. Am. Phys. Soc. 28, 1156 (1983); Los Angeles.

G.D. Kerbel and M.G. McCoy, "ICRF Induced Impurlty Finite Poloidal Gyroradius Effects," Bull. Am. Phys. Soc, 28, 1042 (1983); Los Angeles,

M.G. McCoy and G.D. Kerbel, "Charge Exchange Spectra in ICRF Driven Tokamaks." Bu!l. An. Phys. Soc. 2․․, 1042 (1983); Los Angeles.

R.U. Harvey, J.Y. Hsu, S.C. Chiu, M.G. MrCoy and G.D. Kerbel. "Production of a Sloshiling Ion Distribution by ICRF lieating Jn a Tokamak."

Bul2. Am, Phys. Soc. 28, 1030 (1983): l.os Angeles. 
G.D. Kerbel and M.G. McCoy, "ICRF Catalyzed Fusion Reactivity Enhancement," Annual Controlled Fusion Theory Conf., Lake Tahoe (1984), 2R18.

R.S. Devoto. A.A. Mirin and E.J. Horowitz, "Calculation of Multi-Ion Trapping Rates in Tandem Mirror End Cel1s," Annual Controlled Fusion Theory Conf., Lake Tahoe (1984), 183.

R.S. Devoto, L.L. LoDestro and A.A. Mirin, "Scaling Laws for Trapping Rates of Passing lons in Tanden Mirror End Cells," Bull. Am. Phys. Soc. 29 (Boston, 1984), 1227.

M.G. McCoy, G.D. Kerbel, J, Killeen, R.W. Harvey and S.C. Chiu, "Fokker-Planck Study of ICRF Fusion Reactivity Enhancement,"

Bu11. Am. Phys. Soc. 29, (Boston, 1984), 1273.

G.D. Kerbe1, H.G. McCoy and G.P. Tomaschke, "Scanning Charge Exchange Analyzer Diagnostic for Bounce-Averaged Fokker-Planck simulations of ICRF Heated Tokamaks," Bull. Am. Phys. Soc. 29 (Boston. 1984), 1397.

R.S. Devoto, L.L. LoDestro and A.A. Mirin, "Derivation of Scaling Laws for Trapping Rates of Passing Ions in a Mirror Cell, "Annual Concrolled Fusion Theory Meeting, Madison (1985), 156.

M.G. McCay, G.D. KerbeI and R.W. Harvey, "Trapped Electron Effects on Electrical Conductivity and Runaway Production," Annual Controlled Fusion Theory Meeting, Madison (1985), IPS.

A.A. Mirin, A.C. England, H.W. Hendel, D.L. Jassby and E.B. Nieschmidt, "Fokker-Planck Analysis of Neutron Production in Beam-Injected TFTR Plasmas," Bull. Am. Phys. Soc. 30 (San Diego, 1985), 1521.

G.R. Smith and G.D. Kerbel, "Ion-Cyclotron Power Absorpcion in Tandem Mirrors," Bul1. Am. Phys. Soc. 30 (San Diego, 1985), 1588.

M.C. McCoy and C.D. Kerbel, "Three-Dimensional Simulations of Radio Frequency Heating," Bull. Am, Phys. Soc. 30 (San Diego, 1985). 1591.

R.W. Harvey, M.G. McCoy, G.D. Kerbel, R.T. Snider and R. Prater, "Quasilinear and Steady Electric Field Eftects on Electron Cyclotron Heating," Annual Controlled Fusion Theory Meeting. New York (1986), 2C17.

M.R. Franz and G.D. Kerbel, "A Relativistic Fokker-Planck Algorlthm for Computing ECRH in Tokamaks," Annual Controlled Fusion Theory Meeting. New York (1986), 1D38.

P. L. Colestock, R.J. Kashulaa and G.D. Kerbel. "The High-Frequency Conductivjey in a Plasma with Parallel Magnetic Fleld Gradients," Annual Controlled Fuston Theory Meeting. New York (1986), 3c)2.

(a. b. Kerbel. "Orbit Integral propagators." Asmual Controlled Fusion Theory Meting. New York (1986), 3C13.

R.S Devoto and A.A. Miris. "Neutral-Beam Currant Drive in a Large Sijerconduct ing Tokamak," BuJl. All. Phys. Soc. 31 1]986), IS19. 
D.L. Jassby, H W. Hendel, A.C. England, D.C. McCune, J.D. Strachan. H.H. Towner, M.C. Zarnstorff and A.A. Mirin, "Time Evolution of Beam-Target, Beam-Beam and Thermonuclear Neutron Production," Bu11. Am. Phys. Soc. 31 (1986), 1610 .

H.W. Hendel, T.J. Brudner, A.C. England, D.L. Jassby, D.C. McCune. E.B. Nteschmidt, J.D. Strachan, M.C. Zarnstorff and A.A. Mirin. "Neut ron Source Strength and $Q$ Results for TFTR Plasmas with Injected Neut ral-Bearr Powers up to $15 \mathrm{MW}, "$ Bull. Am. Phys. Soc. 31 (1986), 1414.

H.H. Towner, A.C. England, R.J. Goldston, H.W. Hende1, D.L. Jassby. R.T. MeCann, D.C. HeCune, E.B. Nieschmidt, M.C. Zarnstorff and A.A. Miriu. "Modeling TFTR Neutron Production Rates using SNAP," Bul1. Am. Phys. Soc. $31(1986), 1610$.

G.P. Tomaschke, G.D. Kerbe1 and M.G. McCoy, "A Finite-Banana-Width. Bounce-Averaged, Cokker-Planck Collision Operator for Tokamaks." Bull. Am. Phys. Soc. 31 (Baltimore, 1986), 1400.

R.W. Harvey, M.G. McCoy and G.D. Kerbel, "Quasilinear, DC Electric Field, and Trapped Particle Eftects on Electron Cyclotron Heating and Current Drive," Bul1. Am. Phys. Soc. 31 (Baltimore, 1986), 1517.

M.G. McCoy, G.D. Kerbel and M. Franz, "A Bounce-Averaged Fokker-Planck Package for Tokamaks," Bull. An. Phys. Soc. 31 (Baltimore, 1986), 1523.

G.D. Kerbe1, M. Franz and M.G. McCoy, "A Bounce-Averaged Quasilinear Package for Tokamaks," Bul1. Am. Phys. Soc. 31 (Baltimore, 1986), 1523.

D. Ignat, P. Colestock, D. Blackfield, G. Hammett, G.D. Kerbel, C.K. Phililps, D. Swain and D.G. Swanson, "The ICRF Hearing Scenario for CIT," Bu11. Ans. Phys, Soc. 31 (Baltimore, 1986), 1562.

R.S. Devoto, M.E. Fenstexmacher and A.A. Mirin, "Studies of Neutral Beam Curfent Drfve," Annual Controlled Fusion Theory Conf., San Diego (1987). 1014.

R.W. Harvey, M.G. MeCoy and G.D. Kerbel, "3D Computational Study of Electron Cyclotron Heating and Current Drive،" Annual Controlled Fusion Theory Conf., (San Diego, 1987), 1B5.

G.D. Kerbel, "Spectrally Evolved Resonant Diffusion." Annual Controlled Fusion Theory Conf., (San Diego, 1987), 1D13.

G.D. Kerbel and M.G. Mccoy. "The Many Faces of Resonant Diffusion," Bul1. Ars. Phys. Soc. $\underline{32}$ (San Diego, 1987), 1860.

R.W. Harvey, M.G. McCoy and G.D. Kerbel, "Enchancement of the DC Electric Fleld Runaway Rate by ECH," Bull. Am. Phys. Soc. 32 (San Diego, 1987). 1790 .

G.P. Tomaschke, G.D. Kerbel and M.G. McCoy, "A Finite Banana Wideh, Bounce-Averaged, Fokker-Planck Operator for Tokanaks - Applications to Neoclassical Transport Theory." Annual Controlled Fusion Theory Conf.. Gatl Inburg (1988), 2Cl. 
G.D. Kerbel and M.G. McCoy, "New Features of the NMFECC Fokker-Planck Facility CQL $(02), "$ Annual Controlled Fusion Theory Conf., Gatlinburg (1988), $2 \mathrm{CB}$.

G.D. Kerbel and M.G. McCoy, "Degradation of Neutral Beam Current Drive Effictency by Weak Alfven Turbulence." Bull. Amer. Phys. Soc. 33 (Hollywood. 1988), 1902.

M.G. MeCoy and G.D. Kerbel, "Fokker-Planck Calculations of Neutral Beam Current Drive For ITER," Bull. Amer. Phys. Soc. 33 (Hollywood, 1988), 1902.

D.R. Mikkelsen, R.J. Goldston, B. Grek. H.W. Hendel, R.B. Howell, D.L. Jassby, D.W. Johnson, D.C. McCune, A.A. Mirin, H. Park, A.T. Ransey, G. Schilling, B.C. Stratton, G. Taylor, H.H. Towner and H.C. Zarnstorff, "Comparison of Measured and Calculated DD Neutron Production In TFTR Plasmas and Implications for TFTR DT Operation." Bull. Am. Phys. Soc. 33 (Hollywood, 1988), 1882 .

R.W. Harvey, M, O'Brien, M.G. McCoy and G.D. Kerbel, "Electron Cyclotron Emissions Spectrum calculaced from ECRF Heated Electron Oistributions obtalned with a 3-D Fokker-P1anck Code." Topical Committee on ECE and ECRH (IAEA), Hefei, China (1969). 
Papers and Invited Talks

H.L. Berk, H.P. Furth, D.L. Jassby, R.M. Kulsrud, C.S. L1u,

M.N. Rosenbluth, P.H. Rutherford, F.H. Tenney, T. Jahnson, J, Killeen, A.A. Mirin and M.E. Rensink, "Two Energy Component Toraidal Fusion Devices," Fifth Intl. Conf, on Plasma Physics and Controlled Nuclear Fusion Research, Tokyo (1974), (IAEA, Vienna), 569.

J.A, Byers, J.P. Holdren, J. KIlleen, A.B. Langdon, A.A. Mirin, M. Rensink and C.G. Tull, "Computer Simulation of Pulse Trapping and Pulse Staking of Relativistic Electron Layers in Astron," Phys. Fluids 17, No. 11 (1974), 2061 .

D.L. Jassby, R.M. Kulsrud, F.W. Perkins, J. Kllleen, K.D. Marx, M.G. McCoy, A.A. Mirin, M.E. Rensink and C.G. Tull, "Counterstreaming Ion Tokamak Fusion Reactors," Sixth Int'1. Conf. on Plasma Physics and Controlled Nuclear Fusion Research, Berchtesgaden, FRG (1976), (IAEA, Vienna), II. 435.

T.H. Johnson, J. Killeen, O.A. Anderson and M.E. Rensink, "Guiding Center Simulation of Toroldal Plasmas," J. Comput. Phys. 23 No. 3 (1977), 219.

E.J. Horowitz, "Particle Codes and the Cray-2," Supercomputer 16 (Nov. 1986), 30 .

E.J. Horowitz, "Vectorizing the Interpolation Routines of Particle-in-Cell Codes," J. Comput. Phys. 68 (1987), 56.

J. Killeen, G.D. Kerbel, M.G. HcCoy, A.A. Mirin, E.J. Horowitz and D.E. Shumaker, "Computer Hodels for Kinetic Equations of Magnetically Confined Plasmas," 1987 Int'1. Conf. on Plasma Physics, Kiev.

E.J. Horowitz, D.E. Shumaker and D.V. Anderson, "QN3D, A Three-Dimensional Quasi-Neutral Hybrid Partcle-in-Cell Code with Appilcations to the Tilt Hode Instab1lity in Field Reversed Configurations," submitced to $J$.

Comput. Phys.

H.R. Lewis, D.C. Barnes, R.C. Bishop, N.A. Krall, Z. Mikic, R.D. Milroy, A.A. Mirin, A.G. Sgro, D.E. Shumaker, J.L. Staudenmeier and R.B. Webster, "The Tilt Mode, Turbulence and Transport in Fleld Reversed Configurations," Twelfth Int'l. Conf. on Plasma Physics and Controlled Vuclear Fusion Research, Nice (1988), IAEA-CN-50/C-5-15.

D.V. Anderson, D.E. Shumaker, and E.J. Horowitz, "Plasma Simulation in 3D from Parallel Compuring: Modeling the Tilt Instabllicy," Joint Varenna-Lausanne lnt'l. Workshop on the Theory of Fusion Plasmas, Chexbres, Switzerland (1988), to appeat in Nuovo Cimento. 


\section{Reports, Extended Abstracts and Invited Seminars}

C.G. Tull, T.H. Johnson, M.E. Rensink and J. Killeen, "Guiding Center Particle and Plasma Equilibrium Simulation in Toroidal Systems with Azimuthal Symmetry," Seventh Conf. on the Numerlcal Slmulation of Plasmas, New York (1975), 131.

C.G. Tull, "Guiding Center Simulations of Strong Counterstreaming Ion Currents with Applications to the Counterstreaming Ion Torus," UCRL-52436 (1978).

D.V. Anderson, R.H. Cohen, J.R. Ferguson, B.M. Johnston, C.B. Sharp and P.A. Willmann, "ORBXYZ: A 3D Single Particle Orbit Code for Following Charged Farticle Trajectories in Equilibrium Magnetic FleIds," UCRL-53151 (1981).

E.J. Horowitz and D.V. Anderson, "Development of a 3D Eloctromagnetic Plasma Particle Simulation Code that is Fully Parallelized for the Cray-2," Plasma Simulation Seminar, University of Californla, Berkeley (1985).

D.V. Anderson, E.J, Horowitz, A.E. Koniges and D.E. Shumaker, "Fully Implicit Solucion of Maxwell's Equations In Three Dimensions by Preconditioned Conjugate Gradient Methods with an Application to Reversed Field Conf1gurations," 13th European Conf. on Controlled Fusfon and Plasma Heating, Schllersee, FRG (1986), Vol, I, 353.

E.J. Horawitz and D.E. Shumaker, "3-D Hybrid Code to Model the Tilt Hode in FRC's," Eighth U.S. Compact Toroid Symposium, College Park (19B7).

E.J. Horowitz, "QN3D: A PIC Ccde for the cray-2," Twelfth Gonf, on the Numerical Simulation of Plasmas, San Francisco (2987), IT6.

\section{Conference Abstracts}

T. Johnson, J. Kflleen and M.E. Rensink "Guiding Center SImulation of the Two Component Torus," Bull. Am. Phys. Soc. 19, 974 (1974); Albuquerque.

J.A. Byers and A.A. Mirin, "Formation of Reversed Fleld EquLijbria during Large Current Neutral Injection into Kagnetic Mirror Target Plasma," Bull. Am. Phys. Soc. 19, 921 (1974); Albuquerque.

J.A. Byers, A.A. Mirln and D.R. Schnabel, "Simulation of Self-Consistent Magnetic Fields in 2XIIB," Annual Meeting on Theoretical Aspects of Controlled Thermonuclear Regearch, Rosslyn (1975), 12.

C.G. Tu11, D.L. Jassby, T.A, Johnson, J. Killeen and M.E. Rensink, "Steady State Simulations of the Counterstreaming Ion Torus (CIT) Fusion Reactor," Bul1. Am. Phys. Soc. 21, 1064 (1976): San Franclsco.

T.H. Johnson, J. Killeen, H.E. Rensink and C.G. Tull, 21. .rsification of Gulding Center Simulation Methods," Bull. An. Phys. Soc. 21, 1038 (1976); San Francisco.

C.C. Tull, J. Killeen and M.E. Rensink, "A Steady state Gulding Center Model for the Counteratreaming Ion Torus (CIT), "Annual Concroiled Fusion Theory Conf., San Diego (1977), I13. 
E.J. Horow1tz, D.V. Anderson and D.E. Shumaker, "A Fully Vectorized 3-D Particle Code for the Cray-2 Multiprocessor," Bull. Am. Phys. Soc. 30 (San Diego, 1985). 1565.

D.V. Anderson, E.J. Horowitz, A.E. Koniges and D.E. Shumaker, "A Fully Implicit Fleld Solver for 3D Particle Simulation Codes," Annual Controlled Fusion Theory Meeting, New York (1986), 2C18.

E.J. Horowitz and D.E. Shumaker, "Normal Mode Simulation as a Test for 3-D Particle-In-Cell Code," Annual Controlled Fusion Theory Meeting, New York (1986), 2619.

E.J. Horowitz and D.E. Shumaker, "Hodelling the Rigid Rotor Problem with a 3-D Particle-In-Cell Code," Bull. Am. Phys. Soc. 31 (Baltimore, 1986), 1526.

E.J. Horowitz and D.E. Shumaker, "A 3-D PIC Code to Model the Tilt Mode In FRC's," Annual Controlled Fusion Theory Conf., San Diego (1987), ID2.

D.E. Shunaker, A.A. Mirin, E.J. Horowitz and D.A. Callahan, "Simulation of the T11t Mode in the FRG," Bull. Am. Fhys. Soc. 32 (San Diego, 1987), 1727.

D.E. Shumaker, "3-D Hybrid Perticle Simulation of the Tilt Mode in the Fleld-Reversed Conflguration," Bull. Amer. Phys. Soc. 33 (Hollywood, 19BB), 2003. 
Appendix E - Efficient Nunerical Algorithms and Programining Techniques References

Papers and Invited Talks

M.G. KeGoy, A.A. Mirin and J. Killeen, "FPPAC-A Two-Dimensional

Kultispecies Nonlinear Fokker-Planck Package," Comput. Phys. Commun. $\underline{24}$, No. 1 (1981), 37 .

A.I. Shestakov and D.V. Anderson, "ILUCG2: Subprograms for the Solution of a Linear Axisymetcle Matrix Equation Arising from a 9-pofnt 2D

Discretization," Comput. Phys. Commun. 30 (1983), 31.

D.V. Anderson and A.I. Shestakov, "ICCG2: Subprograms for the Solution of a Linear Symmetric Matrix Equation Arising from a 9-polnt 2D Discretization," Comput. Phys. Commun. 30 (1983), 37.

D.V. Anderson, "IlUCG3: Subprograms for the Solution of a linear Asymmetric Matrix Equation Arising from $7,15,19$, or 27 point 3D Discretizations," Comput. Phys. Commun. 30 (1983), 43.

D.V. Anderson. "ICCG3: Subprograms for the Solution of a Linear Symmetric Marrix Equation Arising from 7, 15, 19, or 27 point 3D Discretizations," Comput. Phys. Commun. 10 (1983), 51.

D.V. Anderson, E.J, Horowitz and A.E. Koniges, "Parallel Computing and Multitasking," 8th Europhys lcs Conf. on Compttatlonel Physics and Computing is Plasma Physles, Garmisch-Partenkirchen, FRG (1986); Comput. Phys .

Comnun. 43 (1986), 69 .

E.J. Horowitz, "Particle Codes and the Cray-2," Supercomputer 16 (Nov. 1986), 30 .

A.E. Koniges and D.V. Anderson, "ILUBCG2: A Preconditioned Blconjugate Gradient Routine for the Solution of Linear AxLsymetric Matrix Equations Arising from 9-Point Discretizations," Comput. Phys. Comoun. 43 (1987). 297.

A.E. Koniges and D,V. Anderson, "Vectorized and Multitasked Software Packages for Solving Asymetric Matrix Equations," in

Advances in Computer Methods for Partial Differential Equations IV, R. Vichnevetsky and R.S. Stepleman, Editors (INACS, New Jersey, 1987), 118.

A.E. Koniges, "Vectorized and Multitasked Software Packages for Solving Asymmetric Matrix Equations," Sixth IMACS Int'l. Symposium on Computer Methods for PDE's, Bethlehem (1987) (Invited Talk).

D.v. Anderson, R. Gruber, A.R. Fry and A. Roy, "Parallel Cyclic Reduction Algorithm for the Direct Solution of Large Block-Tridiagonal Systems." Proc. First Int'1. Conf. on Industrial and Applied Mathematics. Paris (1987), 18.

D.V. Anderson, A.R. Fry, R. Gruber and A. Roy, "Plasma Physies at Glgaflops on the Cray-2," Proc. Third Int'1. Symposium on Science and Engineering on Cray Supercoinputers, Minneapolis (1987) (Invited Talk). 
D.v. Anderson, A.R. Fry, R. Gruber and A. Roy, "Gigaflop Speed Algorithm for the Direct Solution of Large Block-Tridiagonal Systems in 3D Physics Applications," to appear in Computers in Physics.

A.A. Mrin, "Predicting Kultiprocessing Efficlency on che Cray

Hultiprocessors in a (CTSS) Time-Sharing Environment/Application to a 3-D Magnetohydrodynamics Code," Computers in Physics $\underline{2}$ (1988), 62.

D.V. Anderson, A.E. Konlges and D.E. Shumaker, "CPDES2: A Preconditioned Conjugate Gradient Solver for LInear Asymmetric Macrix Equations Arising from Coupled Partial Differential Equations in Two Dimensions," to appear In Comput. Phys. Commun.

D.V. Anderson, A.E. Koniges and D.E. Shumaker, "CPDES3: A Preconditioned Conjugate Gradient Solver for Linear Asymetric Matrix Equations Arising from Coupled Partial Differential Equations in Three Dimensions," to appear in Comput. Phys. Commun.

A.E. Koniges and C.E. Leith, "Parallel Processing of Random Number Generation for Monte Carlo Turbulence Simulation," to appear in

J. Comput. Phys.

A.A. MIrIn, "Using CRAY Computers for Magnetfc Fusion Energy Applications," to appear in Cray Channels.

D.V. Anderson, D.E. Shumaker, and E.J. Horowitz, "Plasma Simulation in 3D from Parallel Computing: Modeling the Tilt Instability," Joint Varenna-Lausanne Int'1. Workshop on the Theory of Fusion Plasmas, Chexbres, Switzerland (1988), to appear in Nuovo Cimento.

D.V. Anderson and A.E. Konlges, "The Solution of Large Striped Matrix Systems Derived from Multiple Coupled 3D PDE's, "Conference on Iterative Methods for Large Linear Systems, Austin (1988).

Reports, Extended Abstracts and Invited Seminars

A.I. Shestakov, "Users Manual for ILUCG, LLNL Internal Document UCID-18560 (1980).

M.G. McGoy, A.A. Mirin, A.I. Shestakov and J. Killeen, "Two GRAY Optimized Computer Packages: A Nonl Inear Fokker-Planck Equation Solver and an Axisymetric Banded Linear Systems Solver, "Ninth Conf. on the Numerical Simulation of Plasmes, Evanston (1980), PC-8.

D.V. Anderson and A.I. Shestakov, "ICCG and ILUCG Solvers for Two and Three Dimensional PDE's," Tenth Conf. on the Numerical Simulation of Plasmas, San Diego (1983), 2B13.

NHFECC Computational Physics Group, "Running on the Cray-2 and Multitasking," Annual Controlled Fusion Theory Meeting, Madison (1985).

A.E. Koniges and D.V. Anderson, "Conjugate Gradient Baged Matrix Salvers for Coupled Inplicit Equations," Eleventh Int'1. Conf. on the Numerical Simulation of Plasmas, Montreal (1985), 3B5. 
D.V. Anderson, "Computation of Mirror Plasma Equilibria with Multitasking software on the CRAY Parallel Processors," Eleventh Int'1, Conf, on the Numerical Simulation of Plasmas, Montreal (1985), 3A2.

NHFECC Computational Physics Group, "Efficient Use of the Cray Multiprocessors," Fall Meeting of the Division of Plasma Physics of the Ar. Phys. Soc. (San Diego, 1985).

E.J. Borowitz and D.V. Anderson, "Development of a 3D Electromagnetic Plasma Particle Simulation Code that is Fully Parallelized for the Cray- $2, "$ Plasme Slmulation Seminar, University of California, Berkeley (1985).

A.E. Koniges, "Parallel Processing of a Preconditioned Biconjugate-Gradient Algorlthm on Cray Supercomputers, "Second SIAM Conf. on Parallel Processing for Scientific Computing, Norfolk (1985).

A.E. Koniges, "Kulticasking Biconjugate Gradient for the CRAY-2 and CRAY X-MP/22," First RIMSIG Conference, Livermore (1985).

D.V. Anderson, "You Too Can Parallelize Iaplicit Codes," First RIMSIG Conference, Livermore (1985).

A.E. Koniges, "Parallel Processing of a Preconditioned Blconfugate-Gradlent Algorithro on Cray Supercomputers," LLNL Report UCRL.93616 (1985).

D.V. Anderson, E.J. Horowitz, A.E. Koniges and D.E. Shumaker, "Fully Implicit Solution of Maxwell' $z$ Equations in Three Dimensions by Preconditioned Conjugate Gradient Kethods with an Application to Reversed Field Configurations," 13th European Conf. on Conerolled Fusion and Plasma Heating, Schllersee, FRG (1986), Vol. I, 353.

NMFECC Computational Physics Group, "Taking Advantage of Parallelism on the Cray Muleiprocessors, "Annual Controlled Fusion Theory Meeting, New York (1986), 2D39.

NHFECC Computational Physics Group, "Parallel Computing on the NMFEcC System," Bull. Am. Phys, Soc. 31 (1986), 1606.

D.v. Anderson, "Measuring the Gigaflops in a Parallelized Matrix Solver on the Cray-2," Proc. Workshop on Performance Evaluation of Parallel Computers and Prograns, Argonne (1986).

A.E. Konfges, "Yarallel Processing of Physics Codes on Cray Supercomputers," Seminar at Technical University of Prague, Czechoslovakia (1987).

A.A. Mirin, "Predicting Multitasking Overlap on the NMFECC Cray-2," Twelfth Conf. on the Numerical stimulation of Plasmas, San Francisco (1987), CM3.

A.E. Koniges and C.E. Laich, "Mulcitasked Random Number Generation for Monte Carlo Turbulence Simulation," Twelfth Conf. on the Numerinal Simulation of Plasmas, San Francisco (1987), PM24. 
D.V. Anderson, R. Gruber and A. Roy, "Measurements and Estimates of the Performance of the PAMS Plasma Equilibrium Solver on Existing and Nrar-terl Supercomputers." Twelfth Conf. on the Numerlcal Simulacion of Plasmas, San Francisco (1987), PH1L.

D.V. Anderson, R. Gruber and A. Roy, "A Benchmark Code for Multiprocessor Vector Supercomputers," Second 1nt'1. Conf. on Vector and Parajlel Computing Issues, in Applied Research and Development, Tromso, Norway (1988).

\section{Conference Abstracts}

E.J. Horowitz, D.V. Anderson and D.E. Shumaker, "A Fully Vectorized 3.i Particle Code for the Cray+2 Multiprocessor," Bul1. Am. Phys. Soc. 30 (San Diego, 1985), 1565.

D.V. Anderson, E.J. Horowitz, A.E. Koniges and D.E. Shumaker, "Solucion of Vector Fleld Equations by Pre-Conditionec Conjugate Gradient Methods on Three Dimensional Domains," Bull. Am. Phys. Soc. 30 (San Diego, 1985), 1565 .

A.E. Koniges and C.E. Leith, "Numerical Simulation of Drift-Wave Turbulence in a Multitasking Envtronment," Bul1. Am. Phys. Soc. 30 (San Diego, 1985 ). 1371 .

D.V. Anderson, E.J. Horowitz, A.E. Koniges and D.E. Shumaker, "A Fully Implicit Field Solver for 3D Particle Simulation Codes," Annual Controlled Fusion Theory Meeting, New York (1986), 2C18.

A.E. Konlges, "Parallel Computations on the CRAY Multiprocessors: Examples in Linear Algebra and Turbulence," Bul1. Am. Phys. Soc. 31 (Baltimore, 19B6), 1435 .

A.A. Mirin, "Experiences Parallelizing a 3-D MHD Code," Annual Controlled Fuston Theory Conf. San Diego (1987), 1 c19.

A.E. Koniges and D.V. Anderson, "Optimized Matrix Solution Packages for uge In Plasma Physics Codes," Annual Controlled Fusion Theory Conf., San Diego (1987), 2D12.

D.V. Anderson, A.R. Fry, R. Gruber and A. Roy, "Gigaflop Speed Algorithm for 3-D Plasma Equilibrium and Stability Problems," Annual Contralled Fusion Theory Conf., San Diego (1987), 3A6.

A.A. Hrin, "Hultiprocessing Efficiency of 3-D MHD Calculations on the NHFECC Cray-2," Bull. Am. Phys, Soc. 32 (San DLego, 1987), 1855.

D.V. Anderson, A.E. Koniges, M.G. McCoy and A.A. Mirin, "A Survey of I terative Linear Systems Solvers on the NMFECC System,"

Bul1. An. Phys. Soc. 32 (San Diego, 1987), 1855.

A.A. Mirin, D.V. Anderson, M.G. McCoy and S.W. White. "A Survey of DIrect Linear Systems Solvers on the NMFECC System." Annual Controlied Fusion Theory Conf., Gatlitiburg (1988), JDJ?. 
Appendix F - Plasma Turbulence and Anomalous Transport References

Papers and Invited Talks

A.E. Koniges and C.E. Leith, "Statistical Closure Approximations and the Fluctuation-Dissipation Theorem for Drift-Wave Interaction," Phys. Fluids $30(1987), 3065$.

A.E. Koniges and C.E. Leith, "Parallel Processing of Random Number Generation for Monte Carlo Turbulence Simulation," to appear in

J. Corput. Phys.

Reports, Extended Abstracts and Invited Seminars

A.E. Koniges. "Fluctuation-Dissipation Relation for Drift-Wave Interaction," Seminar at Max-Planck Insticut fur Plasmaphysik, Garching, FRG (1987).

A.E. Koniges and C.E. Leith, "Hultitasked Random Number Ceneration for Monte Carlo Turbulence Simulation," Twelfth Conf, on the Numerical Simulation of Plasmas, San Francisco (1987), PM24.

\section{Conference Abstracts}

A.E. Koniges and C.E. Leith, "Numerical Simulation c Drift-Wave Turbulence In a Multitasking Environment," Bull. Am. Phys, '0. 30 (San Diego, 1985), 1371 .

A.E. Konlges and C.E. LeIth, "Turbulence Models in Plasma Physics," Antual Controlled Fusion Theory Meeting, New York (1986), 2C20.

A.E. Konfges and C.E. Lef th, "Markovian Models for Two-Dimensional Collionsional Drift-Wave Turbulence," Bull. Am. Phys. Soc. 32 (5an Diego, $1987), 1890$.

F. Gang, P.H, Diamond and A.E. Koniges, "Statistical Dynamics of a Two-Field Model of Drift-Wave Turbulence," Annual Controlled Fusion Theory Conference, Gatlinburg (1988), 2 D35.

A.E. Koniges, W.P. Dannevik and C.E. Leith, "Pade Approximant Schemes for Incegrating Turbulence Closures of the DIA Type." Bull. Amer. Phys. Soc. 33 (Hollywood, 1988), 2021. 


\section{Appendix G - References Pertaining to Section G}

\section{Papers and Invited Talks}

R.F. Post, K.D. Marx and C.J. Eggens, "Creation of Iransient High-Density Plasmas by Convergent Neutral Beams," Nucl. Fusion 15, No. 4 (1975), 701.

...D. Marx, C.J. Eggens and R.F. Post, "Particle Distributions and Early Phases of Ionization in Proposed Convergent Neutral Beam Experiments," Journal of Applied Physics 4B (1977), 4215.

\section{Conference Abstracts}

R.F. Post, R.D. Marx and C.J. Eggens. "The Use of Convergent Neutral Beans to Create Transient High Density Plasmas," Bull. Am. Phys. Soc. 19, 912 (1974); Albuquerque.

K.D. Marx, C.J. Harcman and R.F. Post, "Approximate Analytical Forinulas for Systems which Employ Convergent Neutral Beams," Bull. Am. Phys. Soc. 20, 1364 (1975); St. Petersburg.

C.J. Hartman, K.D. Marx and R.F. Post, "Numertcal Calculations of Processes In Convergent Neutral Beams," Bull. Am. Phys. Soc. 20, 1365 (1975):

st. Petersburg. 


\section{Review Publications}

Papers and Invited Talks

J. Killeen, "Computer App1lcations in Gontrolled Fusion Researeh,"

Nuc1. Tech. 27 (1975), 107.

J. Killeen, "Computational Plesma Physics," 3rd National Computational Physics Gonference on Partial Differential Equations in Physics, Glasgow (1975), and Computational Methods In Classical and Quantum Physics (Advance Publications Ltd., London, 1976) 83.

J. Killeen, "Computer Models of Magnetically Confined Plasmas," Nuc1. Fusion 16. No. 5 (1976), 841 .

J. Killeen, "Computational Problems in Magnetic Fusion Research," System Modeling and Optimization, (Proc. Tenth IFIP Conf., Springer-Verlag, New York, 1981), 1 .

B.I. Cohen and J. K1lleen, "Computations in Plasma Physics," Phys. Today 36 (1983), 54 .

J. Killeen, "Numerical Solution of Initlal-Value Problems in Plasma Physics," In Compucational Mathematies (Banach Center Publications Serles, Vol. 13), (PWN-Polish Scientific Publishers, Warsaw, 1984), 91.

B.I. Cohen and J. Killeen, "Computations in Plasma Physics," Engineering Progress 11 (1985), 7 .

J. Killeen and B. McNamara, "Computational Plasma Physics and Supercomputers," in Twenty Years of Plasma Physics, (World Scientific Publ. Co., Singapore, 1985), 104.

J. Killeen, "The Role of Supercomputers in Hagnetic Fusion and Energy Research Prograns," In Federal Supercomputer Programs and Policies, Comsittee on Sclence and Technology, House of Representatives (U.S. Govt. Printing office, 1985), p. 122-142.

J. Killeen, "Perspective on the Next Ten Years in Plasma Physics," Particle Accelerators 19 (Gordon and Breach, 1986), 247.

D.V. Anderson, "Parallel Algorithms for Plasma Physics Calculations," Second Graduate Summer Course in Computational Physles, Puidoux. Switzerland (1988), to appear in Computer Physics Reports.

Reports, Extended Abstracts and Inviced Seminars

J. Killeen, "National CTR Computer Center," Seventh Conf. on the Nuperfical Simulation of Plasmas, New York (1975).

J. Killeen, "Numerical Methods in Fusion Research," Third Int'1. Symposium on Computing Methods in Applied Sclences and Englneering. Versallies (1977). 
$-60-$

J. Killeen, "Activities and Plans of the National MFE Computer Center," IEEE Int' 1, Conf. on Plasma Science, Monterey (1978), 292.

3. Killeen, "Magnetic Fusicn Energy and Computers," Proc. 10th IMACS World Congress on System Simulation and Scientific Computation, Montreal (1982), 188 .

J. Killeen, "Plasma Physics Modeling and the Cray-2 Multiprocessor," Seventh Int'1. Conf. on Computing Methods in Applied Sciences and Engineering, Versailles (1985).

\section{Conference Abstracts}

J. Killeen, "Gomputer Models of Magnetically Confined Plasmas," Bull. Am. Phys. Soc. 20, 1358 (1975); St. Petersburg.

2. Other Publications of Group Menbers

Papers and Invited Talks

K.D. Marx, "Reply to Comments by Y.Y. SUn," IEEE Trans. Microwave Theory Tech. 26 (1978).

Reports, Extended Abstracts and Invited Seminars

C.H. Finan, III, "SIGHDT-Atomic and Molecular Cross Sections for Hydrogen Isotcpes." UCRL-51805 (1975).

A.A. Mirin, "The Computational Physics Program of the National HFE Computer Cencer," LLWL. Internal Document UCID-17530 (1977) (and subsequent revisions).

A.A. Mixin, "A Note on Normalization of Vartables and Equations," LLNL Internal Document UCID-18083 (1979). 